\title{
Structure of the Eye and Eyewall of Hurricane Hugo (1989)
}

\author{
Frank D. Marks and Peter G. Black \\ Hurricane Research Division, NOAA/AOML, Miami, Florida \\ Michael T. MONTGOMERY \\ Naval Postgraduate School, Monterey, California \\ ROBERT W. BurPEE* \\ Cooperative Institute for Marine and Atmospheric Studies, University of Miami, Miami, Florida
}

(Manuscript received 31 October 2006, in final form 12 April 2007)

\begin{abstract}
On 15 September 1989, one of NOAA's WP-3D research aircraft, N42RF [lower aircraft (LA)], penetrated the eyewall of Hurricane Hugo. The aircraft had an engine fail in severe turbulence while passing the radius of maximum wind and before entering the eye at $450-\mathrm{m}$ altitude. After the aircraft returned to controlled flight within the 7-km radius eye, it gained altitude gradually as it orbited in the eye. Observations taken during this period provide an updated model of the inner-core structure of an intense hurricane and suggest that LA penetrated an intense cyclonic vorticity maximum adjacent to the strongest convection in the eyewall [eyewall vorticity maximum (EVM)]. This EVM was distinct from the vortex-scale cyclonic circulation observed to orbit within the eye three times during the $1 \mathrm{~h}$ that LA circled in the eye. At the time, Hugo had been deepening rapidly for $12 \mathrm{~h}$. The maximum flight-level tangential wind was $89 \mathrm{~m} \mathrm{~s}^{-1}$ at a radius of $12.5 \mathrm{~km}$; however, the primary vortex peak tangential wind, derived from a 100-s filter of the flight-level data, was estimated to be $70 \mathrm{~m} \mathrm{~s}^{-1}$, also at $12.5-\mathrm{km}$ radius. The primary vortex tangential wind was in approximate gradient wind balance, was characterized by a peak in angular velocity just inside the radius of maximum wind, and had an annular vorticity structure slightly interior to the angular velocity maximum. The EVM along the aircraft's track was roughly $1 \mathrm{~km}$ in diameter with a peak cyclonic vorticity of $1.25 \times 10^{-1} \mathrm{~s}^{-1}$. The larger circulation center, with a diameter $>15 \mathrm{~km}$, was observed within the eye and exhibited an average orbital period of $19 \mathrm{~min}$. This period is about the same as that of the angular velocity maximum of the axisymmetric mean vortex and is in reasonable agreement with recent theoretical and model predictions of a persistent trochoidal "wobble" of circulation centers in mature hurricane-like vortices. This study is the first with in situ documentation of these vortical entities, which were recently hypothesized to be elements of a lower-tropospheric eye/eyewall mixing mechanism that supports strong storms.
\end{abstract}

\section{Introduction}

Hugo strengthened to a hurricane on 13 September 1989 some $2000 \mathrm{~km}$ east of the Lesser Antilles (Case and Mayfield 1990). On 15 September, Hugo was moving toward the west-northwest at 7-8 $\mathrm{m} \mathrm{s}^{-1}$ and deepening rapidly for several hours. At about 1330 UTC, scientists with the Hurricane Research Division (HRD)

\footnotetext{
* Deceased.
}

Corresponding author address: Frank D. Marks, Hurricane Research Division, NOAA/AOML, Miami, FL 33149.

E-mail: frank.marks@noaa.gov of the National Oceanic and Atmospheric Administration (NOAA)/Atlantic Oceanographic and Meteorological Laboratory were finalizing plans in Barbados for a two-aircraft research experiment later in the day with the NOAA WP-3Ds (N42RF and N43RF) in what they expected to be a strong Saffir-Simpson (Saffir 1973; Simpson 1974) category-3 tropical cyclone (TC). The research mission into Hugo called for N42RF to be the lower aircraft (hereinafter referred to as LA) at $450 \mathrm{~m}$ and N43RF to be the upper aircraft (hereinafter referred to as UA) at 500-hPa pressure altitude. At that time, the HRD scientists were unaware that satellite meteorologists at the National Hurricane Center were estimating that Hugo's minimum surface pressure $\left(P_{\mathrm{SC}}\right)$ 


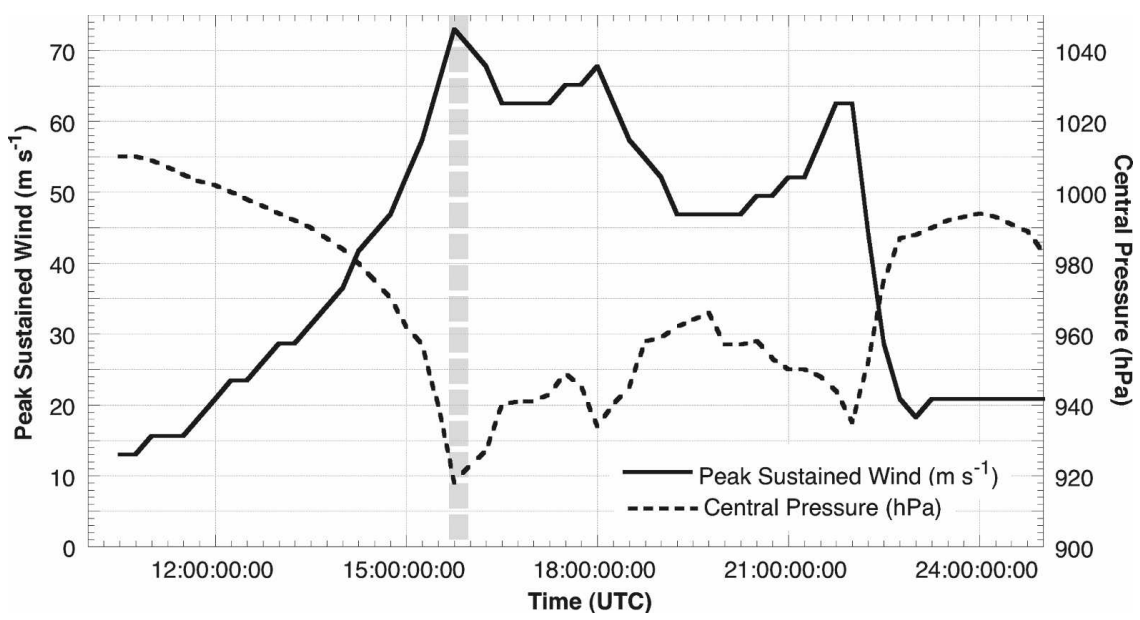

FIG. 1. Time series of the estimated $P_{\mathrm{SC}}$ and the $V_{\max }$ in Hugo for 10-24 Sep 1989. The vertical dashed line denotes the time of the LA flight on 15 Sep.

decreased from 957 to $938 \mathrm{hPa}$ from 0600 to $1400 \mathrm{UTC}$ (Fig. 1). An objective, infrared satellite intensity scheme (E. N. Rappaport 1990, personal communication) later estimated Hugo's deepening rate to be an extreme $6.3 \mathrm{hPa} \mathrm{h}^{-1}$ over $3.5 \mathrm{~h}$. For a few hours, at least, this rate was more than the deepening of $1.75 \mathrm{hPa}$ $\mathrm{h}^{-1}$ over $24 \mathrm{~h}$ required to satisfy the Holliday and Thompson (1979) threshold for "rapidly deepening" TCs in the western Pacific Ocean.

At about 1500 UTC, both NOAA aircraft departed Barbados Airport and the scientific part of the mission began $\sim 350 \mathrm{~km}$ west-southwest of the center of the TC. By chance, a U.S. Air Force reconnaissance WC-130 aircraft (hereinafter referred to as AFA), which was temporarily based in Antigua, joined the two NOAA aircraft in Hugo and began its operational responsibilities flying at $700-\mathrm{hPa}$ pressure altitude a few minutes after LA entered the storm.

As LA approached the storm, its lower fuselage radar ${ }^{1}$ depicted Hugo's horizontal radar structure (Fig. 2a) in units of equivalent reflectivity factor (hereinafter called reflectivity). The large-scale radar structure re-

\footnotetext{
${ }^{1}$ Jorgensen (1984a) describes the characteristics of the WP-3D lower fuselage and tail radars.
}

veals that Hugo's eyewall was very intense, with reflectivity $>46 \mathrm{~dB} Z$, which usually makes up $<0.5 \%$ of the area in the eyewall (cf. Fig. 10 in Marks 1985), covering $>33 \%$ of the eyewall area. An expanded view of the radar reflectivity within $60 \mathrm{~km}$ of the center (Fig. 2b) shows that the eyewall reflectivity, averaged by radius around Hugo, was a maximum at $\sim 12 \mathrm{~km}$. In the southwest quadrant near where LA penetrated the eyewall, the peak reflectivity was $>50 \mathrm{dBZ}$. The outer radius of the low reflectivities corresponding to the eye is $\sim 7 \mathrm{~km}$. At LA's low altitude, the radar did not detect a clear eye because of the presence of sea clutter. ${ }^{2}$

On LA's first, and only, low-level pass through the eyewall (hereinafter referred to as the penetration), it encountered severe turbulence in three updraftdowndraft couplets. During the penetration, LA's inside right engine became overheated and the pilot shut it down near the inner edge of the eyewall. Having reached the eye, but with LA still carrying almost all of its fuel, the crew found itself just $270 \mathrm{~m}$ above an angrylooking sea surface, surrounded by strong cumulonimbi

\footnotetext{
${ }^{2}$ Sea clutter can also be seen in the low-reflectivity region surrounding the eye as linear features of high reflectivity emanating from the flight track.
}

FIG. 2. (a) Ground tracks for LA from 1710 to 1738 UTC and AFA from 1723 to 1805 UTC, and LA lower fuselage radar image for 1724:50 UTC. The radar image domain is $240 \mathrm{~km} \times$ $240 \mathrm{~km}$. The short- and long-dashed line depict the LA and AFA flight tracks, respectively. (b) The storm-relative aircraft track for LA from 1719 to 1730 UTC and UA from 1810 to 1844 UTC superimposed on radar data for 1726 UTC. The composite domain is $120 \mathrm{~km} \times 120 \mathrm{~km}$. The solid line depicts the LA track, and the dashed line depicts the UA track, with circles at 30 -s intervals. The red dotted line is the storm track from 1715 to 1845 UTC. In both images the reflectivity is denoted by colors ( $\mathrm{dBZ}$ ). 

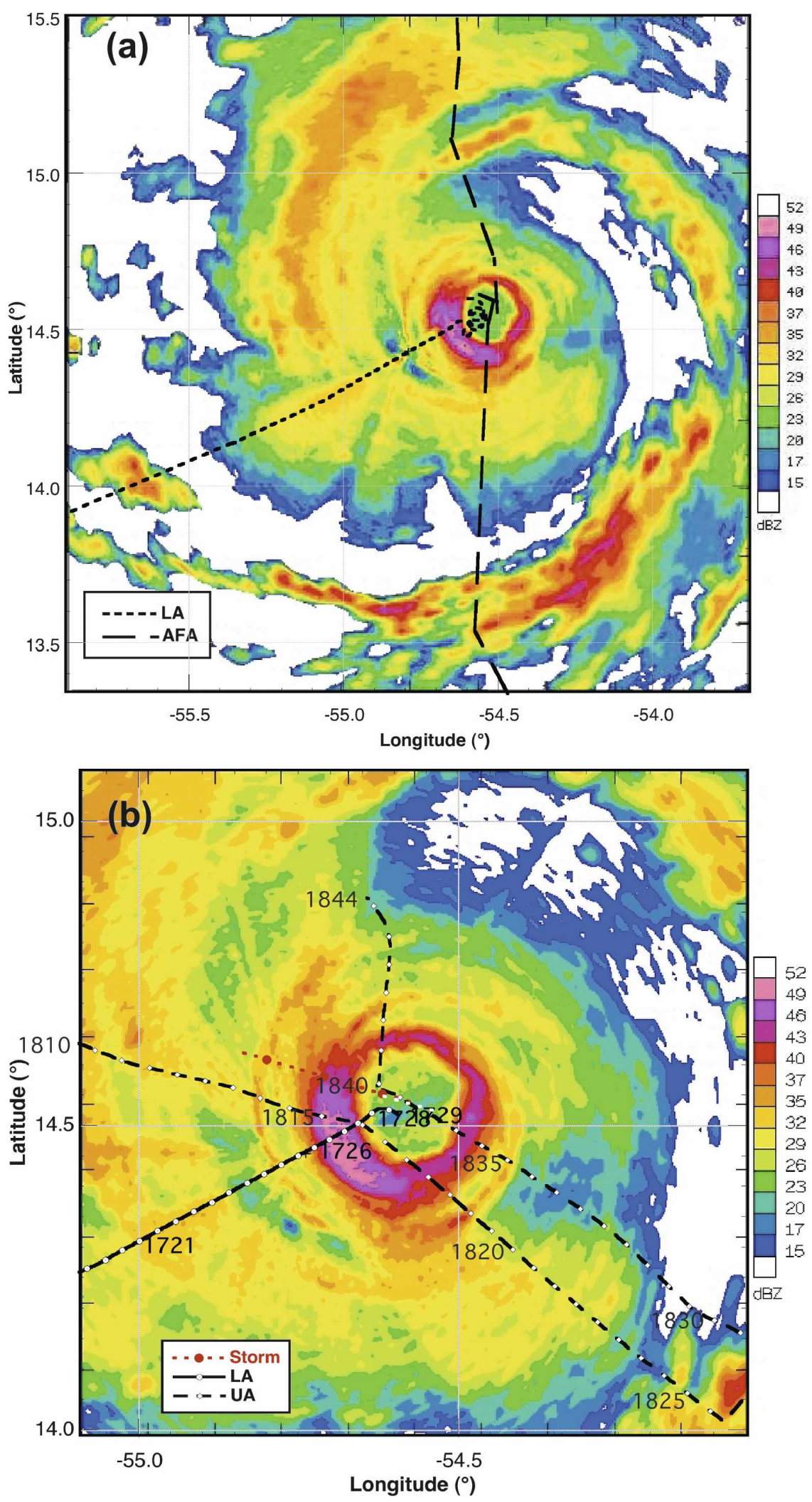
on all sides, and needing a safe way out. The pilots decided to orbit in the eye, dump fuel from the lower fuselage fuel tank, and climb slowly so as not to overheat the three working engines. The crew turned off the radar data system as the fuel was dumped and did not restart it during the remainder of the flight. After LA reached 2200-m altitude, AFA successfully tested a safe way out through the convection on Hugo's northeast side and encouraged LA to follow its course through the eyewall, exit Hugo, and return to Barbados.

The engine failure forced a premature end to LA's research mission. Whereas the aircraft's radar data system recorded reflectivity only on the inbound leg, its flight-level data system operated continuously until LA departed Hugo. When HRD received the processed data, the first two authors examined the data and offered preliminary hypotheses to explain what happened to LA and the crew. It was not until later that dynamical hypotheses were offered to explain the significance of these coherent vortex structures and associated potential vorticity mixing near intense TC eyewalls (Emanuel 1997; Schubert et al. 1999; Kossin and Schubert 2001; Montgomery et al. 2002, 2006; Persing and Montgomery 2003); it will be suggested here that the Hugo data contain corroborating evidence for these theories. This paper is the first observational documentation of the structure and evolution of some of these organized structures within the inner core of an intense TC that Emanuel (1997), Persing and Montgomery (2003), and Montgomery et al. (2006) hypothesized to be essential elements of a lower-tropospheric eye/ eyewall mixing mechanism that supports intense storms.

\section{LA flight pattern and storm structure}

\section{a. The penetration}

As LA approached Hugo from the west-southwest, the flight-level wind at 450-m altitude increased slowly to $\sim 25 \mathrm{~m} \mathrm{~s}^{-1}$ at $\sim 150$-km radius (1708 UTC) and then slowly increased to $<40 \mathrm{~m} \mathrm{~s}^{-1}$ within a few kilometers of the outer edge of the eyewall (1725 UTC in Fig. 3b). At the outer edge of the eyewall, ${ }^{3}$ the winds increased rapidly to $89 \mathrm{~m} \mathrm{~s}^{-1}$ within $\sim 1.5 \mathrm{~min}$ and the reflectivity intensified from 37 to $49 \mathrm{dBZ}$ in less than a minute (Fig. $3 a)$. During the eyewall traverse, the aircraft intercepted three distinct updraft-downdraft couplets and a fourth updraft as indicated on Fig. 3: 1) a $6 \mathrm{~m} \mathrm{~s}^{-1}$ updraft at 1727:10 UTC and a $-6 \mathrm{~m} \mathrm{~s}^{-1}$ downdraft at 1727:20 UTC; 2) a $9 \mathrm{~m} \mathrm{~s}^{-1}$ updraft at 1727:35 UTC and

\footnotetext{
${ }^{3}$ Defined as the inner and outer edges of the intense reflectivity at altitudes $<3 \mathrm{~km}$ and denoted in Fig. $3 \mathrm{a}$.
}

$\mathrm{a}-10 \mathrm{~m} \mathrm{~s}^{-1}$ downdraft at 1727:39 UTC; 3 ) a $21 \mathrm{~m} \mathrm{~s}^{-1}$ updraft from 1727:55 to 1728 UTC and a $-8 \mathrm{~m} \mathrm{~s}^{-1}$ downdraft at 1728:04 UTC; and 4) a $12 \mathrm{~m} \mathrm{~s}^{-1}$ updraft at 1728:06 UTC. The magnitude of the peak up- and downdrafts in these couplets was in the highest $2 \%-3 \%$ observed at any altitude in the eyewall region of a mature hurricane by Black et al. (1996; cf. Fig. 5).

During this period, there were two peaks in the flight-level horizontal wind in Fig. 3b. The first peak (labeled I) of $89 \mathrm{~m} \mathrm{~s}^{-1}$ coincided with the updraft in the second couplet, and was followed by a decrease to 60 $\mathrm{m} \mathrm{s}^{-1}$, coincident with the downdraft in the same couplet. The second peak (labeled II) of $82 \mathrm{~m} \mathrm{~s}^{-1}$ occurred at 1728:02 UTC, nearly coincident with the updraft in the third updraft-downdraft couplet. From 1728:02 to 1728:08 UTC $(\sim 0.5 \mathrm{~km})$, the wind speed dropped from 82 to $25 \mathrm{~m} \mathrm{~s}^{-1}$ and shifted direction from $340^{\circ}$ to $25^{\circ}$, suggesting the presence of an intense cyclonic vorticity maximum [hereinafter referred to as an eyewall vorticity maximum (EVM)] on the inside edge of the main wind maximum. It was during this time that one of the aircraft engines failed (at $\sim 1728: 07$ UTC). ${ }^{4}$ Figure $3 b$ also shows that surface pressure $\left(P_{s}\right)^{5}$ was dropping steadily as the aircraft approached the eyewall. In the third downdraft, coincident with the sharp drop in wind speed and change in wind direction, $P_{s}$ rapidly decreased to $916 \mathrm{hPa}, 8 \mathrm{hPa}$ lower than the mean value of $924 \mathrm{hPa}$ observed in the eye.

Outside the eyewall (1721-1726 UTC) the equivalent potential temperature $\left(\theta_{e}\right)$ remained near $357 \mathrm{~K}$. During the next $2 \min \theta_{e}$ was $\sim 360 \mathrm{~K}$ in the outer portion of the eyewall. As the aircraft penetrated the three updraft-downdraft couplets and the strongest reflectivity region, $\theta_{e}$ climbed steadily from 360 to $365 \mathrm{~K}$, before climbing to a peak of $374 \mathrm{~K}$ at 1728:30 UTC, $\sim 2-3 \mathrm{~km}$ inside the eyewall reflectivity maximum.

Figure 3a shows a vertical cross section of reflectivity from the tail Doppler radar on $\mathrm{LA}^{6}$ and vertical velocity $(w)$ along the flight track in Fig. 2b. Outside the eyewall (1721-1726 UTC) the vertical reflectivity structure was characterized by a distinct "bright band," or region of enhanced reflectivity $>30 \mathrm{~dB} Z$ that was near the altitude of the $0^{\circ} \mathrm{C}$ isotherm. This type of reflectivity structure was indicative of stratiform precipitation processes where the rain is a result of melting of snow (e.g., Marks and Houze 1987; Marks et al. 1992). Above the bright band, the reflectivity was sharply lower in the

\footnotetext{
${ }^{4}$ Although this vorticity maximum was relatively intense, there is no indication that penetrating it caused the aircraft engine failure.

${ }^{5}$ Nomenclature is defined in the appendix.

${ }^{6}$ Marks and Houze (1987) and Black et al. (1996) describe how the vertical incidence tail Doppler radar data are processed.
} 


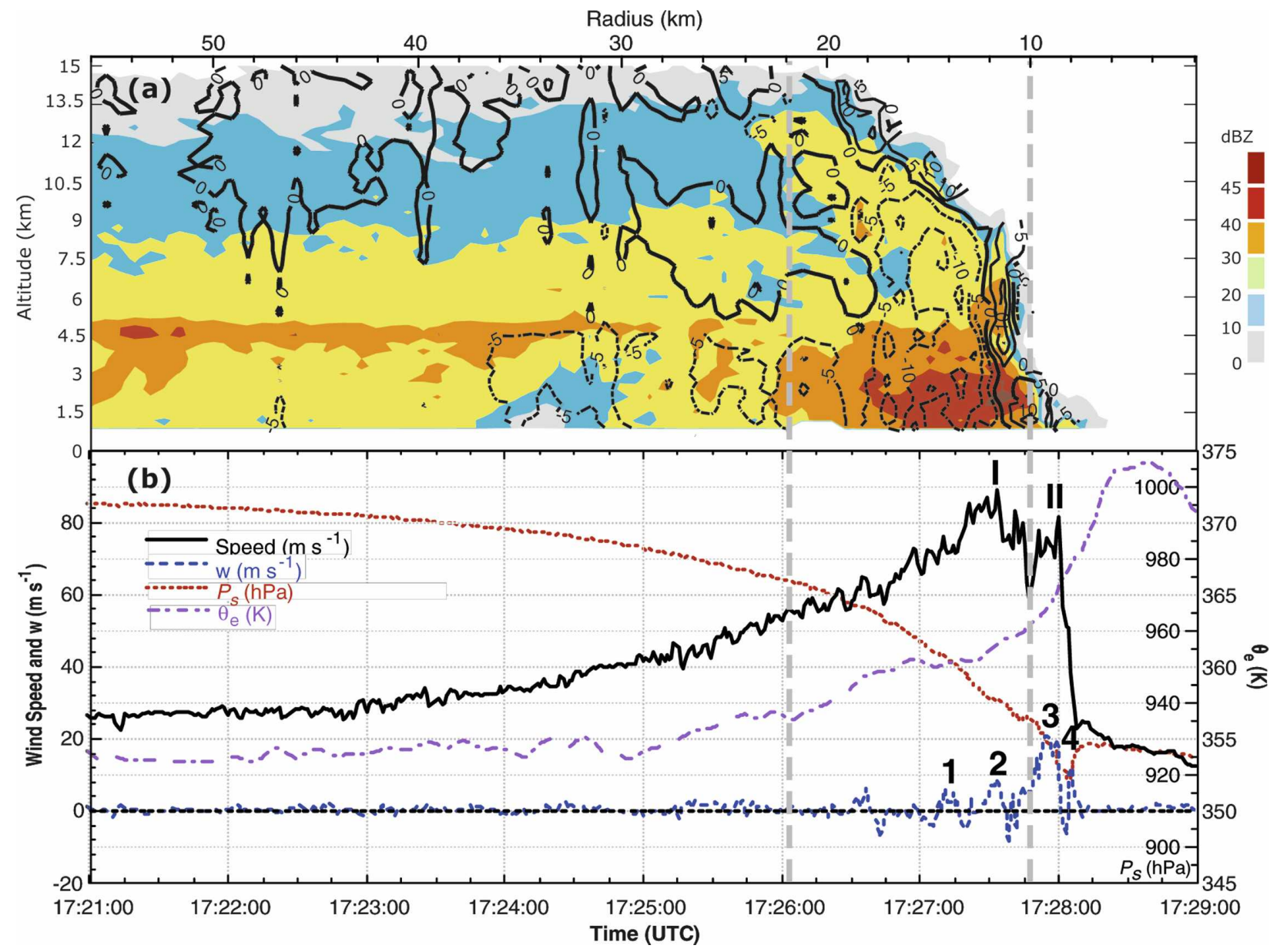

FIG. 3. (a) Time-height cross section of vertical incidence tail radar reflectivity (dBZ) from LA for 1721-1728 UTC. The LA flight track was at $450 \mathrm{~m}$. Solid and dashed lines denote vertical velocity, and radar reflectivity is denoted by colors using the color scale on the right. (b) Time series plots of $w$, horizontal wind speed, $P_{s}$, and $\theta_{e}$ for the period 1721-1730 UTC. Updrafts labeled 1, 2, 3, and 4 and wind speed peaks I and II are described in the text. The thick dashed lines in (b) approximately delineate the outer and inner radii of strong eyewall reflectivity maxima in the lower troposphere $(1<z<5$-km altitude).

snow, and $w$ is weakly upward. Despite the weak updraft, the low reflectivities extend above $15 \mathrm{~km}$, suggesting the ice was lofted in the eyewall and advected outward (e.g., Marks and Houze 1987; Marks et al. 1992). Regions of reflectivity $>30 \mathrm{~dB} Z$ attached to the bright band, extended below it, and sloped outward with decreasing altitude.

The eyewall region (1725:45-1728 UTC) was characterized by intense reflectivity $>45 \mathrm{dBZ}$ at altitudes $<4$ $\mathrm{km}$, and reflectivities $>20 \mathrm{dBZ}$ extending to $13.5-\mathrm{km}$ altitude. Unlike the region outside the eyewall, sharp horizontal reflectivity gradients and stronger vertical velocities, with the sharpest gradients and the strongest up- and downdrafts along the inner edge, were observed in the eyewall region. Distinct updraft maxima with peaks $>10 \mathrm{~m} \mathrm{~s}^{-1}$ existed along the inner edge of the eyewall, resembling bubbles of upward moving air as hypothesized by Marks and Houze (1987) and Black et al. (1996). Downdrafts predominated below 4-km altitude in the region of highest reflectivity with magnitudes $<5 \mathrm{~m} \mathrm{~s}^{-1}$. Above $4-\mathrm{km}$ altitude, however, the largest downdraft magnitudes were $<15 \mathrm{~m} \mathrm{~s}^{-1}$ and were collocated with the reflectivity maximum.

The vertical incidence radar data in Fig. 3a indicate that the first horizontal wind maximum (I) and the second $w$ couplet (labeled 2) were along the inside edge of the eyewall reflectivity maximum below $9-\mathrm{km}$ altitude. The last $w$ couplet (labeled 3 ), the minimum $P_{s}$, large radial $\theta_{e}$ gradient, and the second horizontal wind speed maximum (II) were all radially inward from the heaviest rain area (Fig. 3b), but still within the eyewall cloud boundary at $450-\mathrm{m}$ altitude.

Vertical cross sections of the tail radar perpendicular to aircraft track, shown in Fig. 4, indicate that between the time of the last two updraft-downdraft couplets the aircraft is well within the radar eye at altitudes $>1 \mathrm{~km}$ 


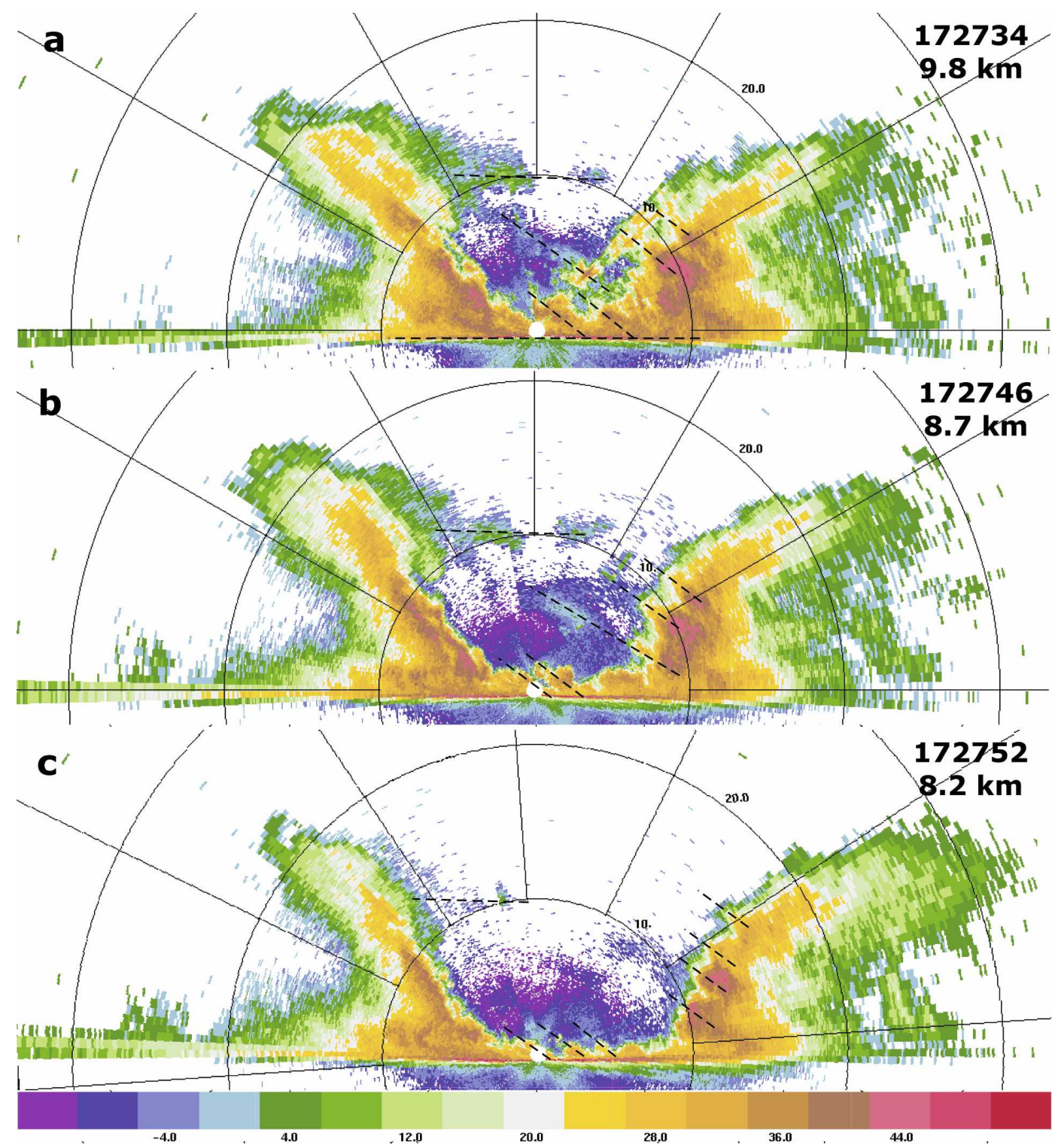

FIG. 4. Vertical cross sections of reflectivity (dBZ) from the tail radar at (a) 1727:34, (b) 1727:46 (8.7 km), and (c) 1727:52 $(8.2 \mathrm{~km})$ oriented perpendicular to the plane in Fig. 3a and the aircraft ground track in Fig. 2a. The aircraft radial distance $(\mathrm{km})$ from the wind circulation center (computed as in section $2 \mathrm{~b}$ ) for each image is listed below the time, e.g., (a) 9.8-, (b) 8.7-, and (c) $8.2-\mathrm{km}$ radius. The aircraft is located at the origin (white square) with range rings from the radar at $10-\mathrm{km}$ intervals. The color scale at the bottom of the figure denotes reflectivity thresholds. Dashed lines denote reflectivity maxima discussed in the text.

(cf. Fig. 3a). The tail radar cross sections show reflectivity maxima protruding from the south eyewall, inclined upwind (from right to left) with increasing altitude at $\sim 35^{\circ}$ angle from the horizontal. Several of these features, inclined along the southwest eyewall, can be seen in radar cross sections and could even be seen at low altitude surrounding the aircraft in the last two cross section in Figs. $4 \mathrm{~b}$ and $4 \mathrm{c}$ (the aircraft appears to fly through one around 1727:52 UTC, during the time of the major updraft). The location of the reflectivity maxima are coherent from one sweep to the next, suggesting they represent maxima of reflectivity along the inside edge of the eyewall inclined upwind with increasing altitude. Figure 5 demonstrates that these features were visually prominent and clearly visible from inside the eye as striations in the cloud field inclined upwind with increasing altitude. The spatial scales and tilts of the cloud striations in Fig. 5 are consistent with those documented by Bluestein and Marks (1987) along the eyewall of Hurricane Diana (1984). Also evident in the 


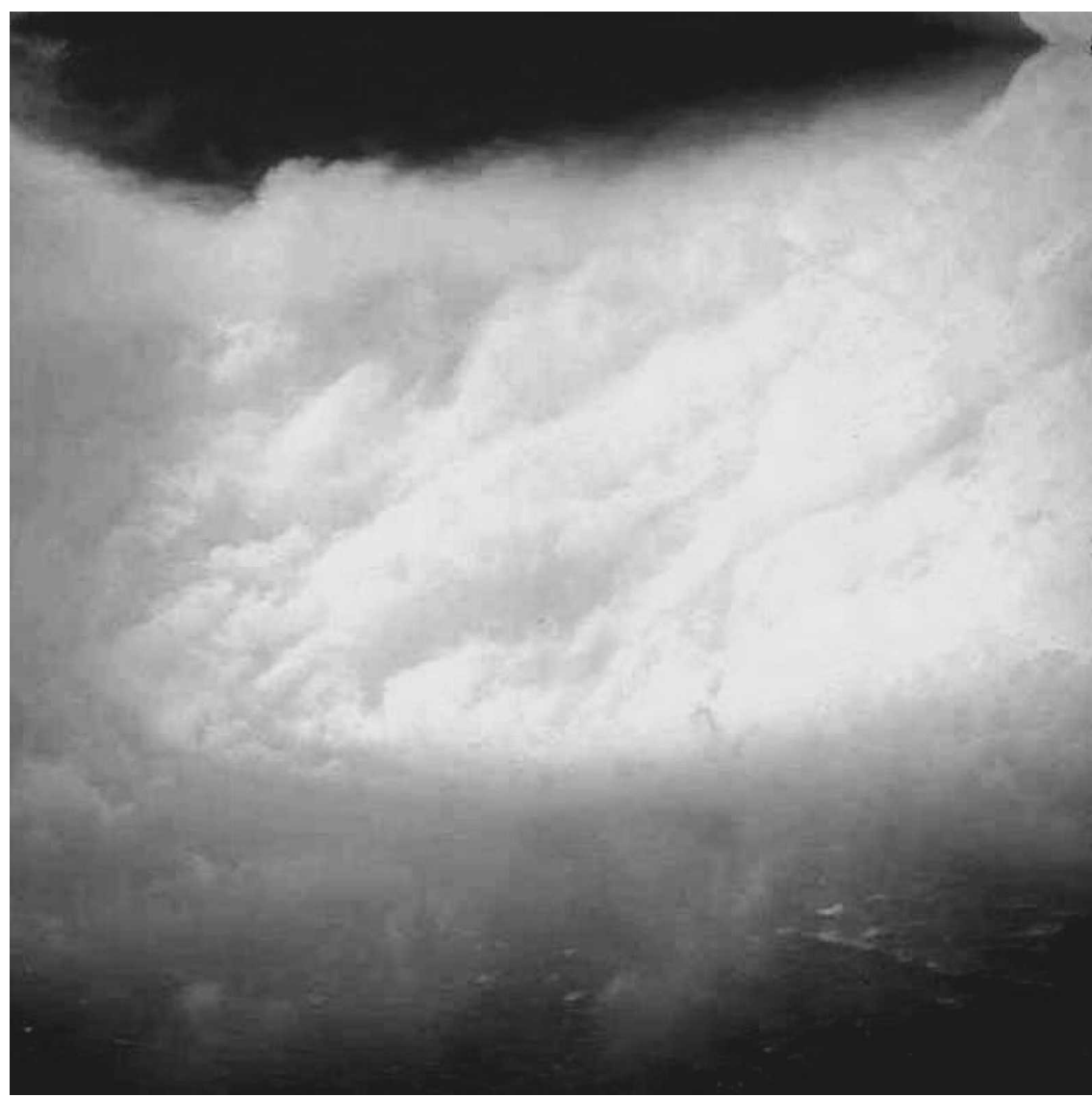

FIG. 5. Photograph of the inside of the eyewall as the aircraft circled inside the eye from 1728 to 1824 UTC showing cloud striations tilted upwind (to the right) with increasing altitude. Also visible is cirrus inside the eye at the upper edge of the eyewall.

tail cross sections was a horizontally aligned region of higher reflectivity at $10-\mathrm{km}$ altitude (denoted by the horizontal dashed line), suggesting the presence of cirrus clouds extending into the eye from the top of the eyewall on this side of the storm (cf. Fletcher et al. 1961). The cirrus is visible on the upper-left-hand side of Fig. 5 and gave the eye a fishbowl appearance.

\section{b. Circling inside the eye}

Figure $2 b$ shows LA entered the highest-reflectivity region in the eyewall prior to penetrating the EVM along the inner edge of the eyewall. A few kilometers south of the track, within the radar eye, a lowreflectivity region was evident at flight level. Upon entering this region, which was clear of any clouds (Fig. 5), LA encountered the flight-level circulation center. The aircraft orbited in this clear patch, climbing to higher altitude, as it began to "follow" this distinct circulation center and pressure perturbation minimum within the eye. Frequent penetrations of this circulation center and pressure minimum ensued during the climb.
Figure 6 depicts the aircraft flight track as LA orbited and slowly climbed in the eye from 1728 to 1826 UTC and time series of $P_{s}$, wind speed, $\theta_{e}$, and radar altitude during LA's 15 orbits in the eye. Figures $6 \mathrm{~b}$ and $6 \mathrm{c}$ show oscillations 3-4 min apart in the $P_{s}$, wind speed, and $\theta_{e}$ time series as LA orbited in the eye. The amplitude of the $P_{s}$ and wind speed oscillations was $7-12 \mathrm{hPa}$ and $10-15 \mathrm{~m} \mathrm{~s}^{-1}$, respectively, while the amplitude of the $\theta_{e}$ oscillations was $5-10 \mathrm{~K}$. During the same period, the radar altitude time series shows the aircraft climbed steadily from $270 \mathrm{~m}$ at 1728:20 UTC to $2200 \mathrm{~m}$ by 1755 UTC, and remained near $2200 \mathrm{~m}$ until exiting the eye at 1826 UTC. As the aircraft climbed, the peak $\theta_{e}$ in each orbit steadily declined from $374 \mathrm{~K}$ upon entering the eye to $365 \mathrm{~K}$ before exiting it.

A linear trend was removed from the $P_{s}$ time series to construct a perturbation pressure, $P_{s}^{\prime}=P_{s}-P_{\text {linear }}$. The trend in Fig. $6 \mathrm{~b}\left(P_{\text {linear }}\right)$ shows that the central pressure was deepening at $\sim 5 \mathrm{hPa} \mathrm{h}^{-1}$, from $925 \mathrm{hPa}$ at 1728 UTC to $920 \mathrm{hPa}$ at 1826 UTC (consistent with the satellite-estimated $6 \mathrm{hPa} \mathrm{h}^{-1}$ over the $3 \mathrm{~h}$ prior to the 

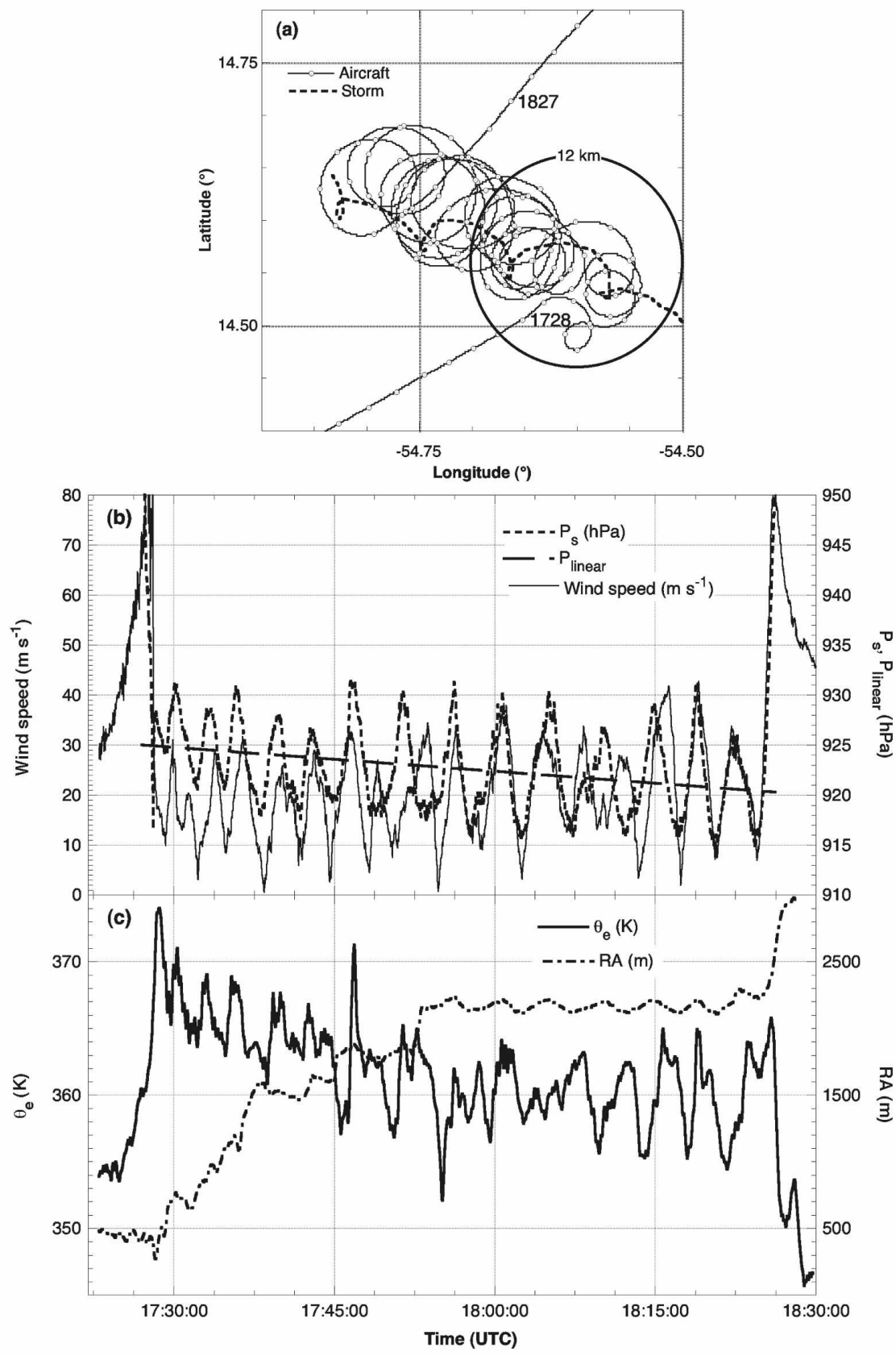

FIG. 6. (a) The LA ground track for 1723-1830 UTC; (b) time series of $P_{s}, P_{\text {linear }}$, and wind speed $\left(\mathrm{m} \mathrm{s}^{-1}\right)$; and (c) time series of $\theta_{e}$ and RA (m) for the same period. In (a) the solid line depicts the flight track with circles at 30-s intervals, the thick dashed line is the storm track from 1715-1824 UTC, and the large circle depicts the radius of eyewall reflectivity maximum $(12 \mathrm{~km})$.

penetration). Superimposed on the periodic pressure signal was a similar, but slightly out of phase, periodicity in the wind speed. That the two time series were not coincident suggests that the wind and pressure centers were not at the same location.

Tracks of the wind and pressure centers were con- structed from the locations of the $P_{s}^{\prime}$ and wind speed minima in Fig. 6b. The two tracks represent the interpolated location (i.e., latitude and longitude) of the $P_{s}^{\prime}$ and wind speed minima over the 3-4 min between aircraft orbits assuming the shortest distance between each successive minima. A refined estimate of the track 

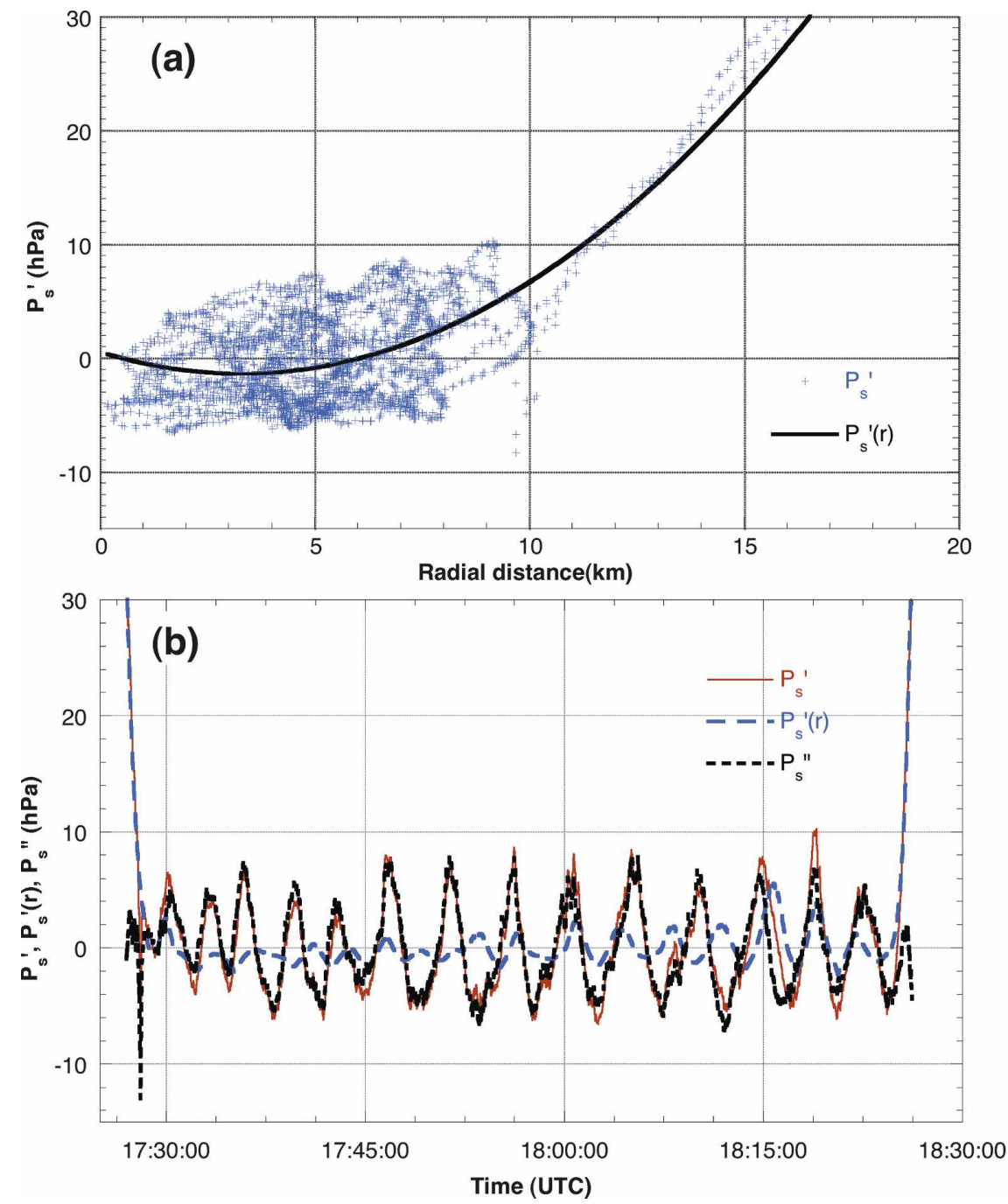

FIG. 7. Perturbation surface pressure within the eye: (a) $P_{s}^{\prime}$ vs radius for 1725-1830 UTC plotted over $P_{s}^{\prime}(r)$, and (b) time series of $P_{s}^{\prime}, P_{s}^{\prime}(r)$, and $P_{s}^{\prime \prime}$ vs time for the period 1725-1824 UTC (see text for details).

of the pressure circulation center was then computed by removing any radial gradient of $P_{s}^{\prime}$ from the time series in Fig. $6 \mathrm{~b}$ using the track of the wind circulations center to calculate the radius of each $P_{s}^{\prime}$ value.

The radial variation of $P_{s}^{\prime}$ within the eyewall is shown in Fig. 7a. The $P_{s}^{\prime}$ signal associated with the EVM is clearly visible at a radial distance of $9.5 \mathrm{~km}$. Inside of that radius there is considerable scatter to $P_{s}^{\prime}$; however, there is a distinct radial variation of $P_{s}^{\prime}$ within the eye with a slight minimum approximately $3-4 \mathrm{~km}$ from the primary vortex center. To minimize the impact of that radial variation in $P_{s}^{\prime}$ on locating each minimum, a quadratic polynomial fit to $P_{s}^{\prime}$ in radius $\left[P_{s}^{\prime}(r)\right]$ was removed, yielding a perturbation pressure $P_{s}^{\prime \prime}=P_{s}^{\prime}-$ $P_{s}^{\prime}(r)$ shown in Fig. 7b. A refined pressure center track was constructed from the interpolated locations of the successive $P_{s}^{\prime \prime}$ minima in Fig. 7b. The final interpolated track of the circulation pressure and wind minima while the aircraft orbited within the eye is depicted in Fig. 8.

The interpolation process indicates that only one pressure and wind center orbited within the eye. Moreover, the wind and pressure centers both exhibited a trochoidal oscillation (e.g., Muramatsu 1986) that completed three orbits with a mean translation of $9 \mathrm{~m} \mathrm{~s}^{-1}$ from $108^{\circ}$ (slightly faster than the recorded best-track speed of $\left.7 \mathrm{~m} \mathrm{~s}^{-1}\right)$. The pressure center lagged the wind center in time, and as seen in Fig. 9, orbited at a larger radius $(\sim 6.5 \mathrm{~km})$ than that for the wind center $(\sim 2$ $\mathrm{km})$. The deviation in position and velocity of the pressure and the wind centers suggests that they orbited 


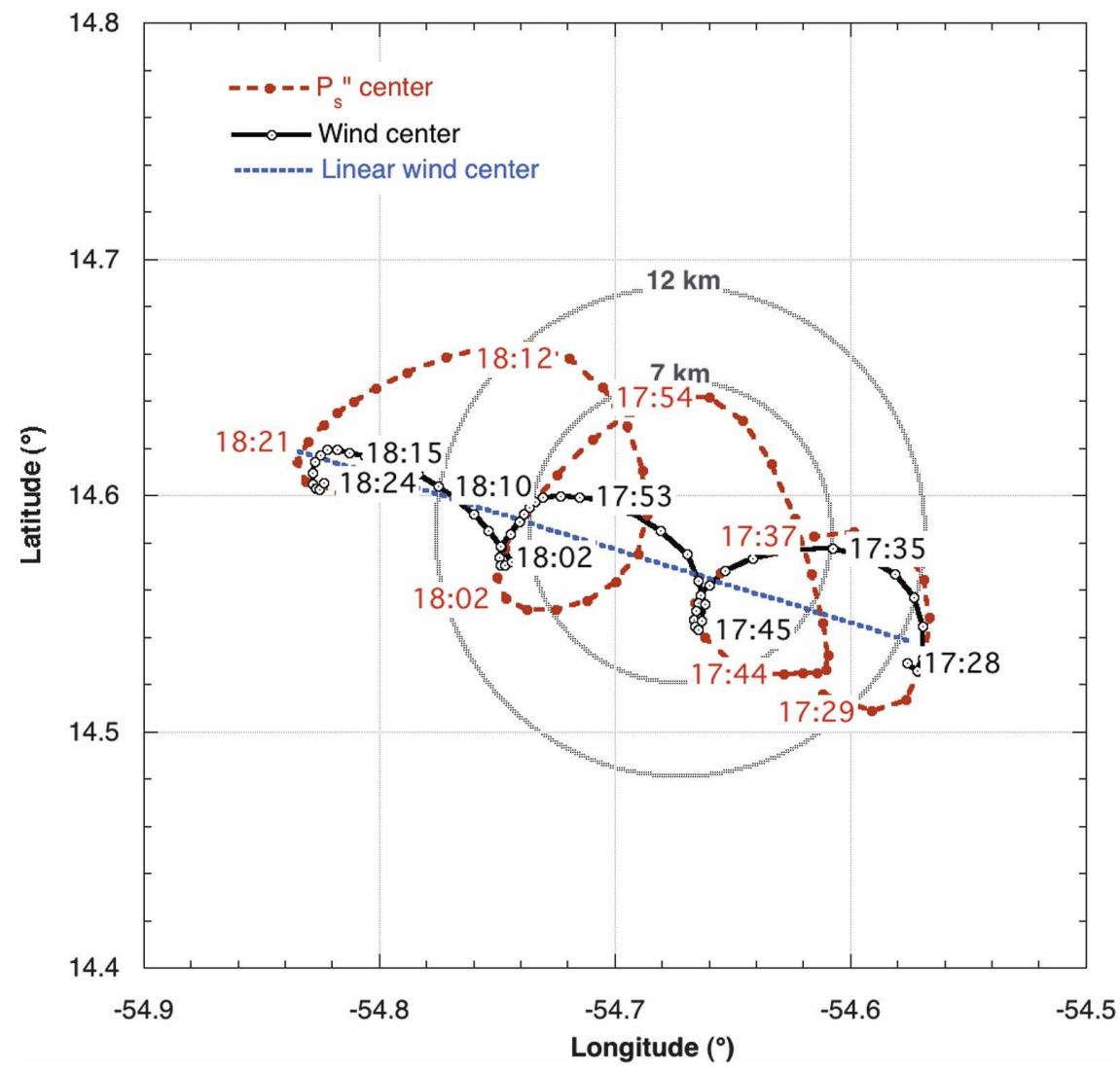

FIG. 8. Track of wind circulation center and $P_{s}^{\prime \prime}$ minimum from 1728 to 1824 UTC. Also plotted is the linear least squares fit to the wind centers over the same period. A 7- and 12-km circle are plotted to show the radii of the radar eye and reflectivity maximum, respectively.

about each other with an angular phase speeds of 27.5 and $12.2 \mathrm{~m} \mathrm{~s}^{-1}$, respectively, implying a rotation period for both of approximately 19 min. Figure 9 also shows that the centroid of the pressure centers was displaced to the east-northeast from the centroid of the wind centers by $2.3 \mathrm{~km}$. As pointed out by Willoughby and Chelmow (1982) such a displacement to the right of track is consistent with the storm motion from ESE at $9 \mathrm{~m} \mathrm{~s}^{-1}$.

While the aircraft orbits revealed separate wind and pressure centers orbiting around in the eye, it is difficult to exclusively associate these changes to the presence of the EVM encountered during the penetration. At the time of the penetration, the pressure and wind centers near the EVM were nearly coincident in space and time (Fig. 6), consistent with a vortical signature. After the penetration the pressure and wind centers separated, returning to near coincidence in space three more times in the ensuing hour. However, Fig. 9 indicates that the relative wind and pressure centers orbited around a common locus and with a common period consistent with a "wobble" of the primary cyclonic circulation within the eye. This wobble is likely not directly related to the $\mathrm{EVM}^{7}$ observed on the penetration given: (i) the lack of coherence in the location of the pressure and wind center; (ii) the smaller pressure perturbation $( \pm 5$ versus $-12 \mathrm{hPa}$ for the EVM); and (iii) closer proximity to the larger circulation center $(2 \mathrm{~km}$ for the wind minimum and $6.5 \mathrm{~km}$ for the pressure minimum versus 9.5 $\mathrm{km}$ for the vorticity maximum). Hence, the penetration should only be used to describe the structure of the EVM and compare it with that of the primary vortex.

To facilitate the analysis of the kinematics of the flow during the penetration, a common vortex-relative coordinate system needs to be defined. As this discussion turns to focus on the separation of the wind field into a primary vortex and a perturbation (using data from only one leg at one level), the wind centers in Fig. 8 were used to navigate the flight-level and radar data for the purpose of computing the radial distance and the

\footnotetext{
${ }^{7}$ While there is little observational evidence that directly links the EVM to the circulation center wobble, there are dynamically consistent arguments that could provide such a relationship (e.g., Schubert et al. 1999; Kossin and Schubert 2001).
} 


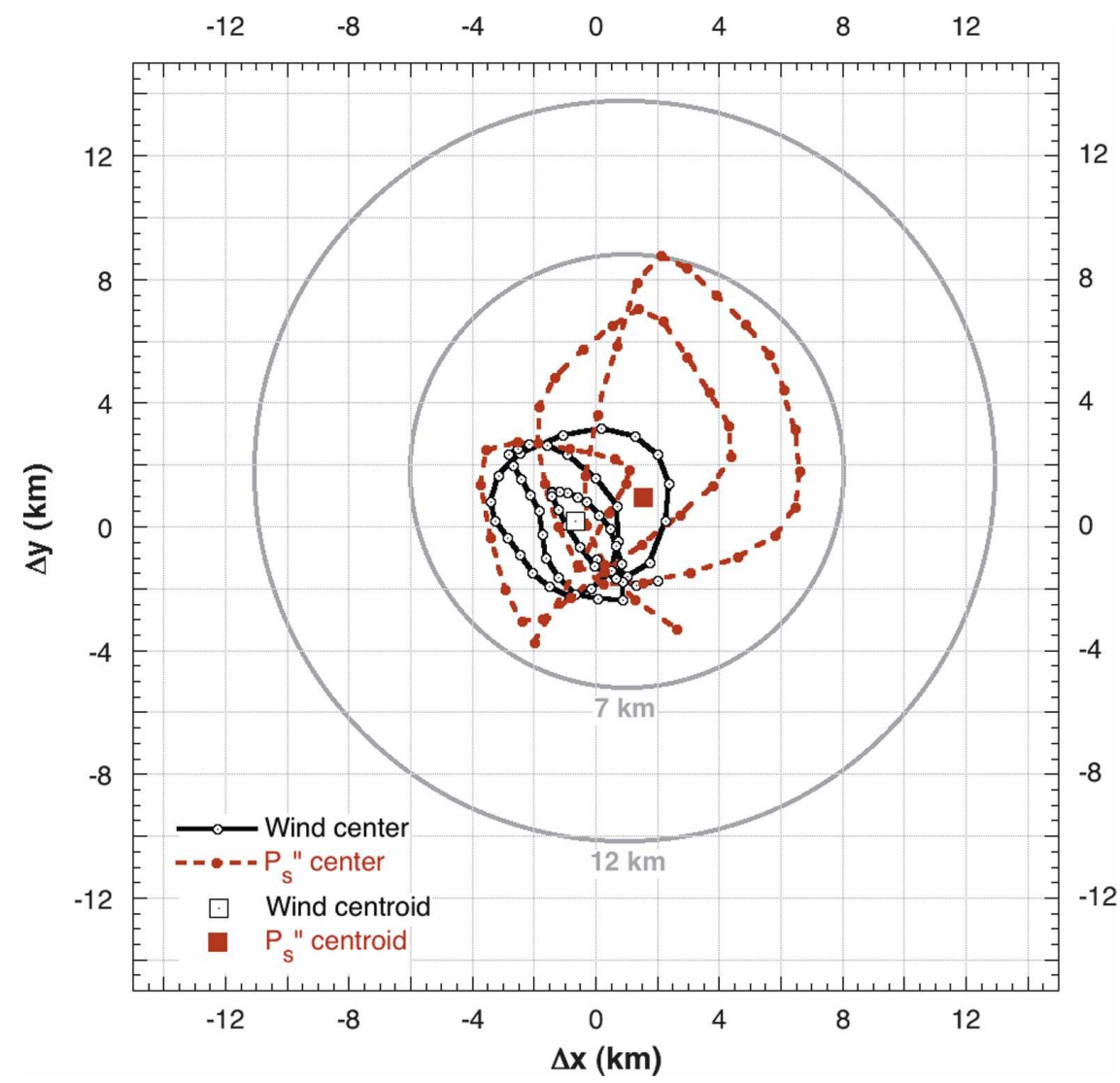

FIG. 9. East-west $(\Delta x)$ and north-south $(\Delta y)$ deviations of storm-relative wind (open circles) and $P_{s}^{\prime \prime}$ centers (solid circles) from the linear least squares fit of the wind centers from 1728 to 1824 UTC. The wind center centroid is denoted by the white square and that for the $P_{s}^{\prime \prime}$ centers by the red square. The 7 - and $12-\mathrm{km}$ circles are centered on the centroid of the pressure centers to denote the radii of the radar eye and reflectivity maximum, respectively. Storm motion was removed.

tangential $V_{\theta}$ and radial $V_{r}$ wind components. The wind center track was extended prior to 1728 UTC by using the center of the radar eye determined from the lower fuselage radar. Inspection of Fig. 9 suggests that the estimated wind center at any time is always $<3 \mathrm{~km}$ from the centroid of all the wind centers, a likely upper bound on the circulation center accuracy. Furthermore, examination of Fig. 8 indicates that when LA completed the penetration at 1728 UTC the linear extrapolation and the trochoidal wind center track were $\leq 2 \mathrm{~km}$ apart. Hence, the linearly extrapolated circulation center on the penetration is likely accurate to within $2 \mathrm{~km}$ for defining $V_{\theta}$ and $V_{r}$.

\section{Defining the primary vortex and perturbation}

\section{a. Partitioning the kinematic flow}

To define the primary vortex using the flight-level data during the penetration from that of the EVM, time and space scales need to be defined to separate the two flows. The scale separation can be done in a number of different ways. In early TC studies compositing flightlevel data was the primary means of defining the mean vortex structure (e.g., Willoughby et al. 1982; Jorgensen 1984a,b; Willoughby 1990), whereas in more recent TC studies, Doppler radar analyses describe the axisymmetric mean and major asymmetries (e.g., Marks et al. 1992; Lee et al. 1994; Roux and Marks 1996). In this case, with one flight leg into the center, it is not possible to provide a complete Doppler analysis; hence, a time filter of the flight-level data will be employed to approximate the two flow scales. As a check on the ability of the filter to separate the two flows, the structure of the filtered flight-level primary vortex will be compared with one defined by an extended velocity track display (EVTD) Doppler analysis (Roux and Marks 1996) from both WP-3D aircraft over a 2-h period starting with LA's initial flight leg (1715 UTC) and including the four UA radial legs between 1810 and 1844 UTC as LA exited the eye (Fig. 2b). 
To determine the time scales of the primary vortex and the perturbations, fast Fourier transforms (FFTs) were performed on the time series of $V_{\theta}, P_{s}$, and vorticity $(\zeta)$ defined as

$$
\zeta=\frac{\partial V_{\theta}}{\partial r}+\frac{V_{\theta}}{r}
$$

where $r$ is radial distance from the storm center defined previously from 1715 to 1729 UTC (the inner $100-\mathrm{km}$ radius). Figure 10 shows the FFT for $V_{\theta}, P_{s}$, and $\zeta .^{8}$ The $V_{\theta}$ and $P_{s}$ FFTs are red, with most of the energy at frequencies $>0.3 \mathrm{~s}^{-1}$ (50-s period; spatial scales $\sim 6$ $\mathrm{km})$. The $\zeta$ FFT, dependent on the gradient of $V_{\theta}$, indicates energy uniformly distributed over the frequency range $0.005-0.5 \mathrm{~s}^{-1}$ (spatial scales of approximately $0.3-$ $24 \mathrm{~km}$ ), with relative peaks at 0.1 and $<0.01 \mathrm{~s}^{-1}$. The peak between 0.09 and $0.13 \mathrm{~s}^{-1}$ is relatively isolated and represents vorticity features on a spatial scale of $\sim 2-\mathrm{km}$ radius, too small to represent the $\sim 12-\mathrm{km}$ radius mean vortex (equivalent to a frequency $\sim 0.01 \mathrm{~s}^{-1}$ ). Hence, to partition the time series into a vortex flow representative of an axisymmetric mean and a perturbation flow about that mean a filter with an $e$-folding time of $100 \mathrm{~s}$ was applied to the time series from 1715 to 1729 UTC. $^{9}$

The flight-level data are separated into two components: 1) the primary vortex represented by the 100 -s filter values, and 2) the perturbation represented by the difference between the full 1-s times series and the filtered values, defined as $X^{\prime}=X_{1-s}-X_{100-s}$, where $X$ represents any scalar value. Figure 11 indicates that the peak of the 100 -s filtered $V_{\theta}$ time series is $71 \mathrm{~m} \mathrm{~s}^{-1}$ at 1727 UTC with a near-linear drop-off to 1729 UTC, smoothing through the abrupt transition at 1728 UTC. The filtered $P_{s}$ drops steadily from 945 to $922 \mathrm{hPa}$ through the same time interval. The filtered $V_{r}$ shows $10 \mathrm{~m} \mathrm{~s}^{-1}$ inflow peaking at 1727:15 UTC, inside the $V_{\theta}$ peak; $V_{r}$ changes to $4 \mathrm{~m} \mathrm{~s}^{-1}$ outflow by 1729 UTC, suggesting strong mean horizontal convergence $(\sim 4 \times$ $10^{-3} \mathrm{~s}^{-1}$ ) defined as

$$
\boldsymbol{\nabla} \cdot V \approx \frac{\partial V_{r}}{\partial r}+\frac{V_{r}}{r}
$$

and passing through $0 \mathrm{~m} \mathrm{~s}^{-1}$ coincident with the $P_{s}$ minimum at 1728:05 UTC.

\footnotetext{
${ }^{8}$ Using (1) the Nyquist frequency for $\zeta$ is $0.5 \mathrm{~Hz}$, whereas for the other two variables it is $1 \mathrm{~Hz}$.

${ }^{9}$ Filters with $e$-folding times between 50 and $100 \mathrm{~s}$ were tried; however, the 100-s filter provided the best match to the axisymmetric mean vortex from the Doppler analysis for $V_{\theta}, \zeta$, and $\Omega$. Shorter-period filters increased the peak $V_{\theta}$ and $\Omega$, while increasing the gradient inside the $r_{\text {max }}$, which increased $\zeta$ well above that in the Doppler analysis.
}

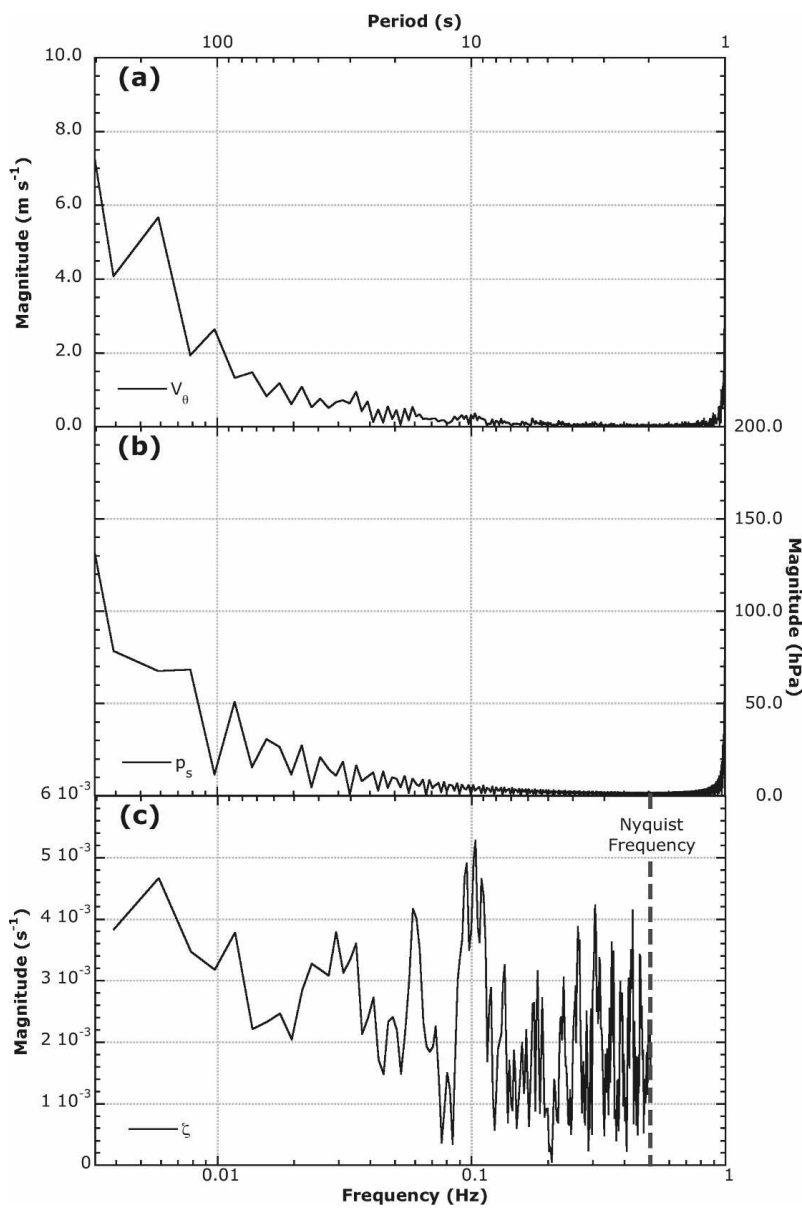

FIG. 10. FFTs of (a) $V_{\theta}$, (b) $P_{s}$, and (c) $\zeta$ for the time series from 1715 to 1729 UTC (the inner $100 \mathrm{~km}$ ). The ordinate is the magnitude of the FFT for that frequency normalized by the number of points in the time series. The Nyquist frequency is $1 \mathrm{~Hz}$ for (a) and (b) and $0.5 \mathrm{~Hz}$ for (c).

Figure 12 shows a comparison of $V_{\theta}, \zeta$, and angular velocity $(\Omega)$ between the 1 - and 100 -s filtered primary vortex defined from the penetration and the EVTDderived axisymmetric mean vortex for the penetration (VTD h1) and the four UA radial legs (VTD i1) shown in Fig. 2b. The magnitude of $V_{\theta}, \Omega$, and $\zeta$ for the four leg EVTD-derived primary vortex compares well with the 100-s filtered vortex, and with the radial structure. This agreement is quite reasonable considering the relatively coarse $1-\mathrm{km}$ radial resolution of the EVTD analysis and the $>1$-h time difference between the single LA leg and the four UA legs, and it supports the use of the 100-s filter to represent the primary vortex.

\section{b. Primary vortex structure}

Figures 13 and 14 depict the 1-s time series, the primary vortex, and the perturbation components with re- 


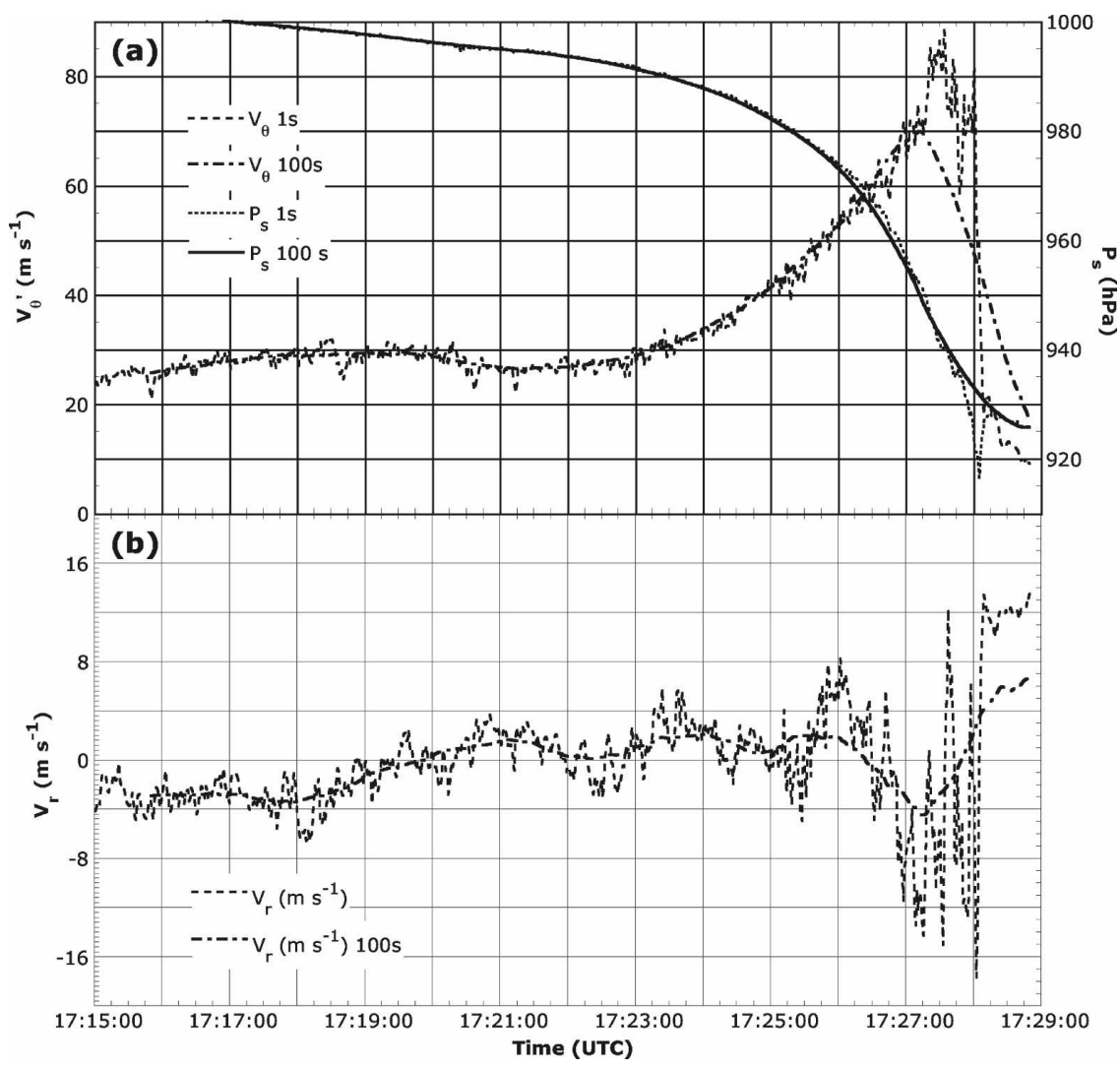

FIG. 11. Time series of 1- and 100-s filtered (a) $V_{\theta}$ and $P_{s}$, and (b) $V_{r}$ from 1715 to 1729 UTC.

spect to radial distance from the wind minima track in Fig. $2 b$. The radius of maximum wind $\left(r_{\max }\right)$ of the primary vortex is $12.5 \mathrm{~km}$ (Fig. 13b), with a near-linear drop in $V_{\theta}<8$-km radius from the center. Moving inward from $13-\mathrm{km}$ radius, $\zeta$ increases rapidly in two discrete steps from $4 \times 10^{-3}$ to $10^{-2} \mathrm{~s}^{-1}$, and then to $3.5 \times 10^{-2} \mathrm{~s}^{-1}$. Each step is $4 \mathrm{~km}$ in width, with the first jump in $\zeta$ at $r_{\text {max }}$, and the second, larger jump at the sharp decrease in the 1-s $V_{\theta}$ time series at 8-km radius.

From $r_{\max }$ to $40-\mathrm{km}$ radius, $V_{\theta}$ decreases approximately as a power law (e.g., Mallen et al. 2005) with increasing radius $(r)$,

$$
V_{\theta}=V_{\theta \max }\left(\frac{r}{r_{\max }}\right)^{\alpha},
$$

where $V_{\theta \max }$ is the value at $r_{\max }$ and $\alpha=-0.83$. Consequently, the vorticity outside $r_{\max }$ steadily decreases to $10^{-4} \mathrm{~s}^{-1}$ at $r=100 \mathrm{~km}$, or about 2.5 times the Coriolis parameter $(f)$ at the latitude of the storm $(f=$ $3.66 \times 10^{-5} \mathrm{~s}^{-1}$ ). Beyond $55-\mathrm{km}$ radius, $V_{\theta}$ increases slightly to near $30 \mathrm{~m} \mathrm{~s}^{-1}$ at $80 \mathrm{~km}$ where it starts slowly decreasing.

The strongest primary vortex inflow observed at flight level is $10 \mathrm{~m} \mathrm{~s}^{-1}$ centered on $r_{\text {max }}$, changing to outflow at 9- and $17-\mathrm{km}$ radius. The mean divergence as defined by (2) was $-6.5 \times 10^{-3} \mathrm{~s}^{-1}$ at radii $<12.5 \mathrm{~km}$ and $1.1 \times 10^{-2} \mathrm{~s}^{-1}$ for radii from 12.5 to $22 \mathrm{~km}$. The primary vortex $w$ (Fig. 14b) is $< \pm 0.5 \mathrm{~m} \mathrm{~s}^{-1}$ outside $r_{\max }$. Inside $r_{\max }$ and straddling the region of maximum convergence, the mean $w$ is $2.2-2.6 \mathrm{~m} \mathrm{~s}^{-1}$, which is comparable to that determined by integrating the mean convergence in this region through a depth of $350-400 \mathrm{~m}$.

The primary vortex $P_{s}$ shows an increase $(\sim 3 \mathrm{hPa}$ $\mathrm{km}^{-1}$ ) across $r_{\max }$ from 8 - to $20-\mathrm{km}$ radius. At radii $<8$ $\mathrm{km}$ the pressure gradient decreases $\left(\sim 1 \mathrm{hPa} \mathrm{km}{ }^{-1}\right)$, reaching a minimum of $925 \mathrm{hPa}$ at $3-\mathrm{km}$ radius. If the flow at flight level is in gradient balance defined as

$$
\frac{V_{G}^{2}}{r}+f V_{G}=\frac{1}{\rho} \frac{\partial p}{\partial r},
$$

where $V_{G}$ is the gradient wind, $p$ is the pressure along the flight track at a constant altitude, and $\rho$ is the density $\left(\mathrm{kg} \mathrm{m}^{-3}\right)$, then $V_{G} \cong V_{\theta}$. Figure 15 a shows the 100 -s filtered flight-level pressure and radar altitude (RA). As with the primary vortex $P_{s}$ in Fig. 14a, the surface 


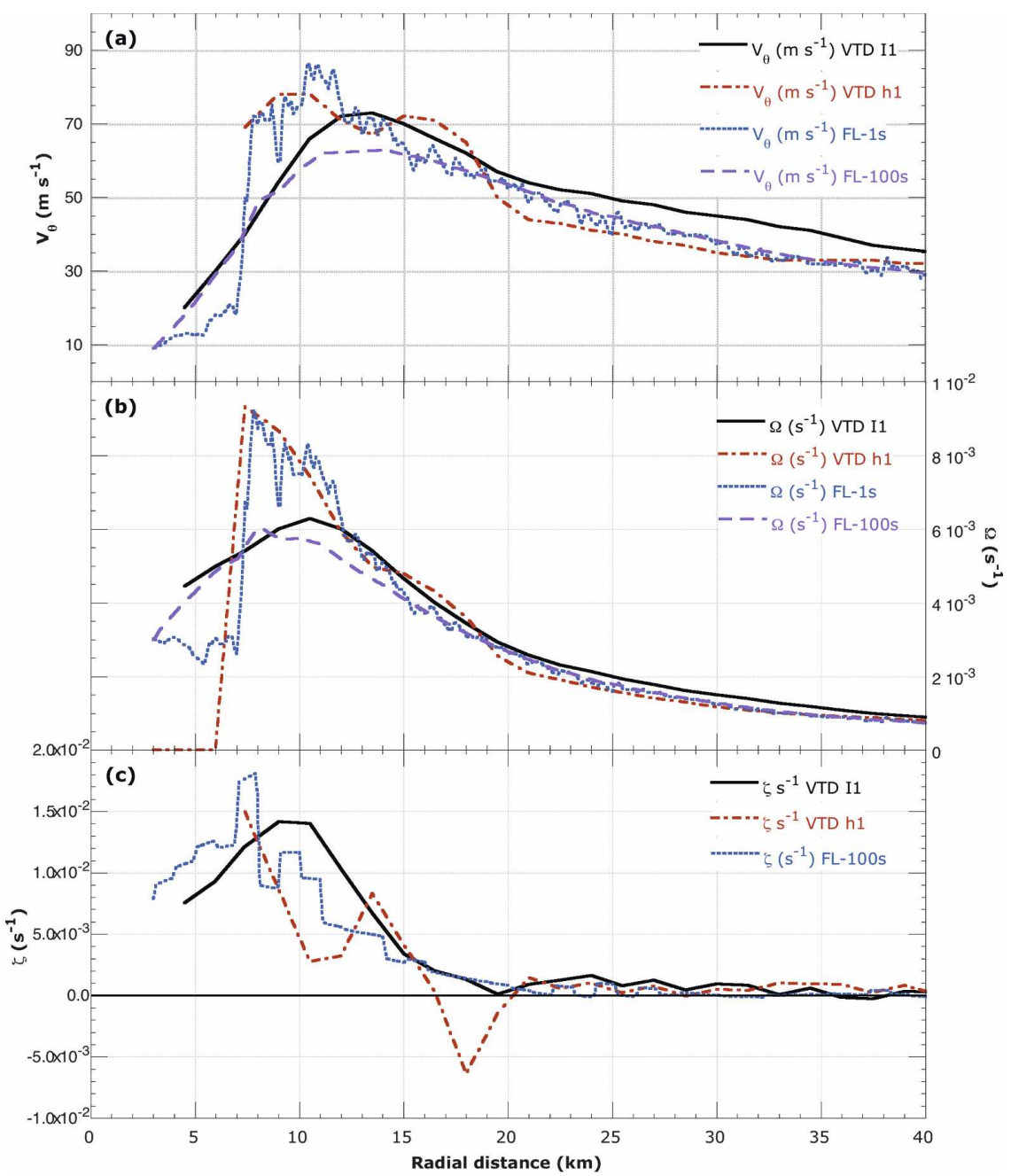

FIG. 12. Comparison of EVTD and 1- and 100-s filtered LA flight-level (a) tangential winds $\left(\mathrm{m} \mathrm{s}^{-1}\right)$, (b) rotation rate $\Omega\left(\mathrm{s}^{-1}\right)$, and (c) vorticity $\left(\mathrm{s}^{-1}\right)$. The EVTD analysis from the single inbound leg on LA is labeled h1, and the EVTD analysis from the four UA legs is labeled i1.

pressure increases slowly $\left(0.25 \mathrm{hPa} \mathrm{km}^{-1}\right)$ from 25 - to $100-\mathrm{km}$ radius, while $\mathrm{RA}$ remains about $450 \mathrm{~m}$. Inside $30-\mathrm{km}$ radius $P_{s}$ drops more sharply $\left(2.2 \mathrm{hPa} \mathrm{km}{ }^{-1}\right)$ toward the center.

Figure $15 \mathrm{~b}$ shows $V_{\theta}$ and $V_{G}$ computed from (4). At radii $<35 \mathrm{~km} V_{G}$ and $V_{\theta}$ are comparable in magnitude with the peak $V_{G}$ of $68 \mathrm{~m} \mathrm{~s}^{-1}$ occurring very close to $r_{\text {max }}$, suggesting that the primary vortex is in approximate gradient balance at these radii. However, at radii $>35 \mathrm{~km}$ there are large differences between $V_{G}$ and $V_{\theta}$. From $35-$ to $70-\mathrm{km}$ radius the flow is subgradient $\left(V_{\theta}<\right.$ $\left.V_{G}\right)$. Willoughby (1990) noted that while the azimuthal mean vortex is usually in gradient balance above the boundary layer, individual legs may contain subgradient or supergradient flows. In the case of this flight leg the inner core approximates gradient balance, while the flow just outside (35-70-km radius) is subgradient with
$V_{\theta}$ approximately $10-15 \mathrm{~m} \mathrm{~s}^{-1}$ less than $V_{G}$. The presence of large regions of gradient imbalance in the primary vortex at radii $>35 \mathrm{~km}$ suggests that other subvortex-scale processes are active.

\section{c. EVM structure}

The perturbation flow (Fig. 13c) clearly shows the presence of the small $(\sim 1 \mathrm{~km}) \mathrm{EVM}^{10}$ centered at $8-\mathrm{km}$ radius $^{11}$ (inside the primary vortex $r_{\text {max }}$ ) with a maxi-

\footnotetext{
${ }^{10}$ It is impossible to be certain about the precise scale of the EVM without information about the structure of the flow perpendicular to the aircraft flight track.

${ }^{11}$ The discrepancy in the radial position of the EVM in Figs. 7 and $13 \mathrm{c}$ is a result of the difference between the actual and linear wind center tracks at the time of the penetration.
} 


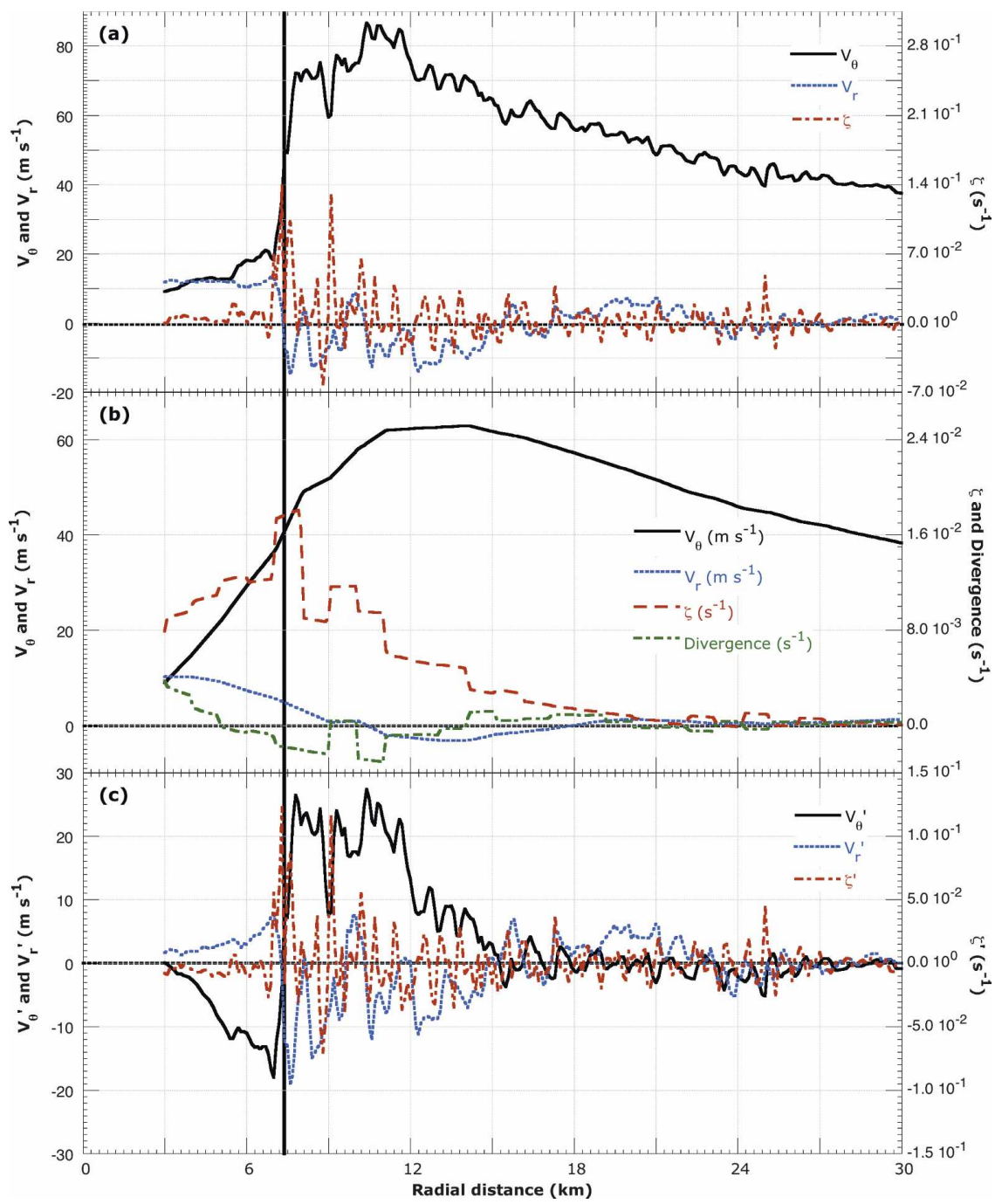

FIG. 13. Plots of (a) 1-s time series, (b) primary vortex, and (c) perturbation components of $V_{\theta}, V_{r}$, and $\zeta$ with respect to radial distance $(R)$ determined from the linear wind center in Fig. 2a. Also plotted in (b) is the primary vortex divergence $\left(\mathrm{s}^{-1}\right)$ computed using $(2)$. The thick vertical line denotes the center of the EVM.

mum cyclonic $V_{\theta}^{\prime}$ of $26 \mathrm{~m} \mathrm{~s}^{-1}$ and a maximum anticyclonic $V_{\theta}^{\prime}$ of $-21 \mathrm{~m} \mathrm{~s}^{-1}$. The EVM's radius of maximum wind $\left(r_{\max }^{\prime}\right)$ is $0.5-1.5 \mathrm{~km}$ depending on how it is defined. As measured from peak to peak, $r_{\max }^{\prime}$ is closer to $0.5 \mathrm{~km}$, but the structure of $V_{\theta}^{\prime}$ suggests a larger feature with $r_{\max }^{\prime}$ closer to $1.5 \mathrm{~km}$. Coincident with the center of the EVM is a peak $\zeta^{\prime}=1.25 \times 10^{-1} \mathrm{~s}^{-1}$, roughly 7 times the magnitude of the primary vortex, and more than three orders of magnitude greater than $f$. Outside the radius of the EVM, at radii $>8 \mathrm{~km} \zeta^{\prime}$ oscillates between anticyclonic and cyclonic with a scale of $1-2 \mathrm{~km}$. The $\zeta^{\prime}$ oscillations outside the primary vortex $r_{\max }$ may be related to vortex Rossby wave/filamentary structures as described by Montgomery and Kallenbach (1997).
At radii $<8 \mathrm{~km} V_{r}^{\prime}$ is outward with a maximum of $8 \mathrm{~m} \mathrm{~s}^{-1}$ located near $r_{\max }^{\prime}$ (Fig. 13c). Across the center of the EVM, $V_{r}^{\prime}$ changes to inflow with a maximum of $-12.5 \mathrm{~m} \mathrm{~s}^{-1}$ also at $r_{\max }^{\prime}$. As radius increases $V_{r}^{\prime}$ oscillates between inflow and outflow with a scale of a 2-3 km, about the same as that for $V_{\theta}^{\prime}$ and $\zeta^{\prime}$, but with a different phase. These oscillations are likely manifestations of other dynamic structures and/or instabilities discussed in section 4 . The perturbation vertical velocity $\left(w^{\prime}\right)$ associated with the EVM (Fig. 14c) is characterized by two updrafts near $r_{\max }^{\prime}$ and a slight downdraft at the center; $w^{\prime}$ is asymmetric about the center with the largest updraft of $16 \mathrm{~m} \mathrm{~s}^{-1}$ at larger radii and the much smaller updraft of $3 \mathrm{~m} \mathrm{~s}^{-1}$ at smaller 


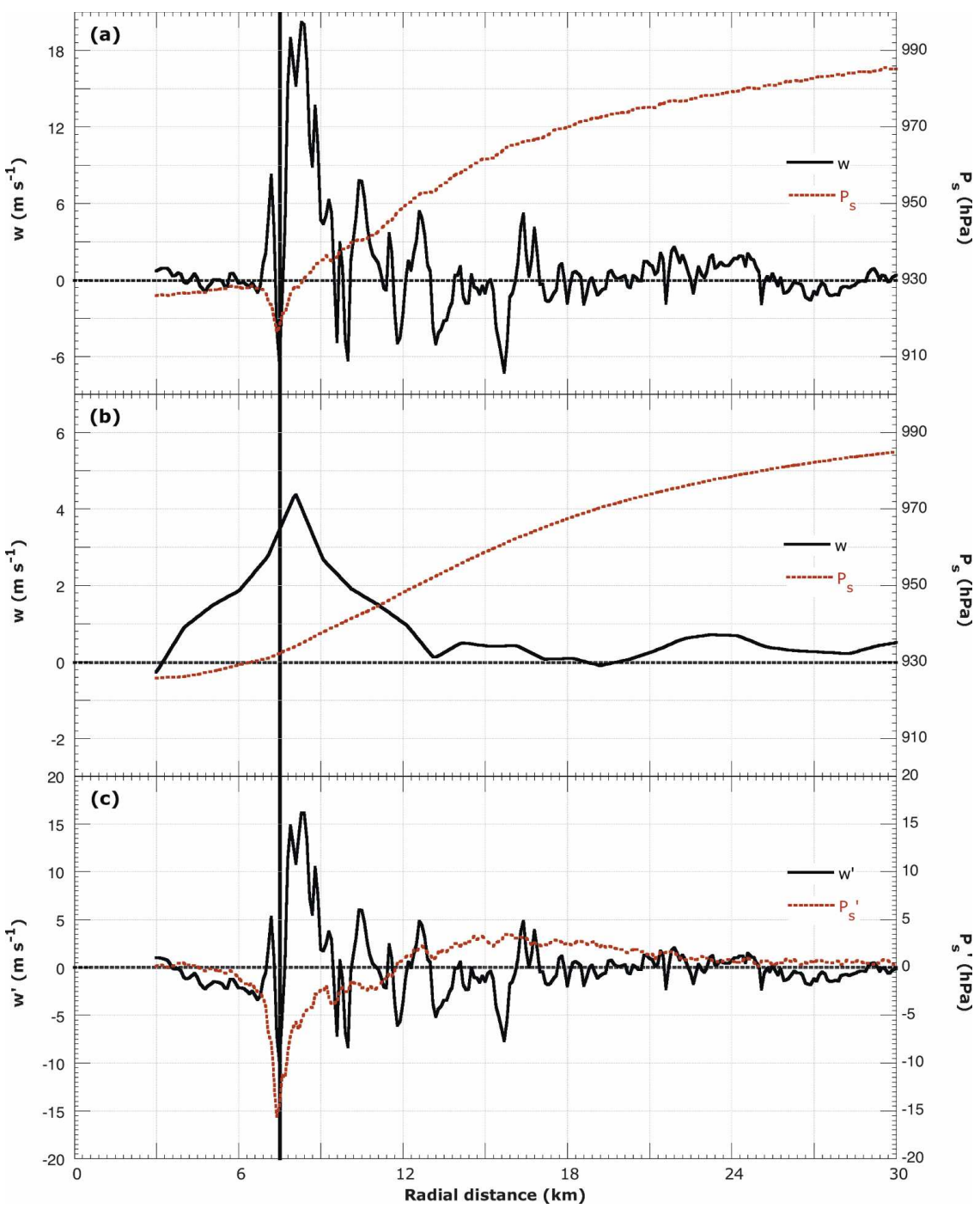

FIG. 14. As in Fig. 13, but for the components of $P_{s}$ and $w$.

radii. At radii $>8 \mathrm{~km}, w^{\prime}$ oscillates with a scale comparable to that of $V_{r}^{\prime}$, suggesting that these $w^{\prime}$ oscillations are forced as a result of local divergence associated with the $V_{r}^{\prime}$ oscillations. Figure 16 suggests that the local divergence computed using $V_{r}^{\prime}$ in (2) is well correlated with $w^{\prime}$ and large enough $\left(\sim 5 \times 10^{-2} \mathrm{~s}^{-1}\right)$ to generate large updrafts through integration over depths $<500 \mathrm{~m}$.

The EVM's $P_{s}^{\prime}$ (Fig. 14c) shows a distinct minimum of $-12.5 \mathrm{hPa}$ at $8-\mathrm{km}$ radius, nearly coincident with the $\zeta^{\prime}$ maximum and the transition from cyclonic to anticyclonic $V_{\theta}$. Between the primary vortex $r_{\max }$ and 22-km radius there is a slight positive $P_{s}^{\prime}$ of $2-3 \mathrm{hPa}$. At radii $>22 \mathrm{~km} P_{s}^{\prime}$ is very close to zero. If the EVM's flow is in cyclostrophic balance defined as

$$
\frac{V_{c}^{2}}{r^{\prime}}=\frac{1}{\rho} \frac{\partial P_{s}^{\prime}}{\partial r^{\prime}}
$$

where $V_{c}$ is the cyclostrophic wind, $P_{s}^{\prime}$ an estimate of the pressure gradient across the EVM, $r^{\prime}$ the radius from the center of the EVM defined as $r^{\prime}=$ radius -8 $\mathrm{km}$, and $\rho$ is the density, then $V_{c} \cong V_{\theta}^{\prime}$ defined in the $r^{\prime}$ coordinates (for $r^{\prime}<0, V_{\theta}^{\prime}$ is multiplied by -1 ). Here $P_{s}^{\prime}$ is used rather than the flight-level perturbation pressure because the aircraft altitude deviated significantly from $450 \mathrm{~m}$ as the aircraft crossed the EVM (Fig. 15a). Figure 17 shows $P_{s}^{\prime}, V_{\theta}^{\prime}$, and $V_{c}$ computed from (5). While $V_{c}$ is noisy, with numerous minima and maxima on either side of $r^{\prime}=0, V_{c}$ and $V_{\theta}^{\prime}$ are comparable in magnitude with the $V_{c}$ peaks occurring at $r_{\max }^{\prime}$ of about 


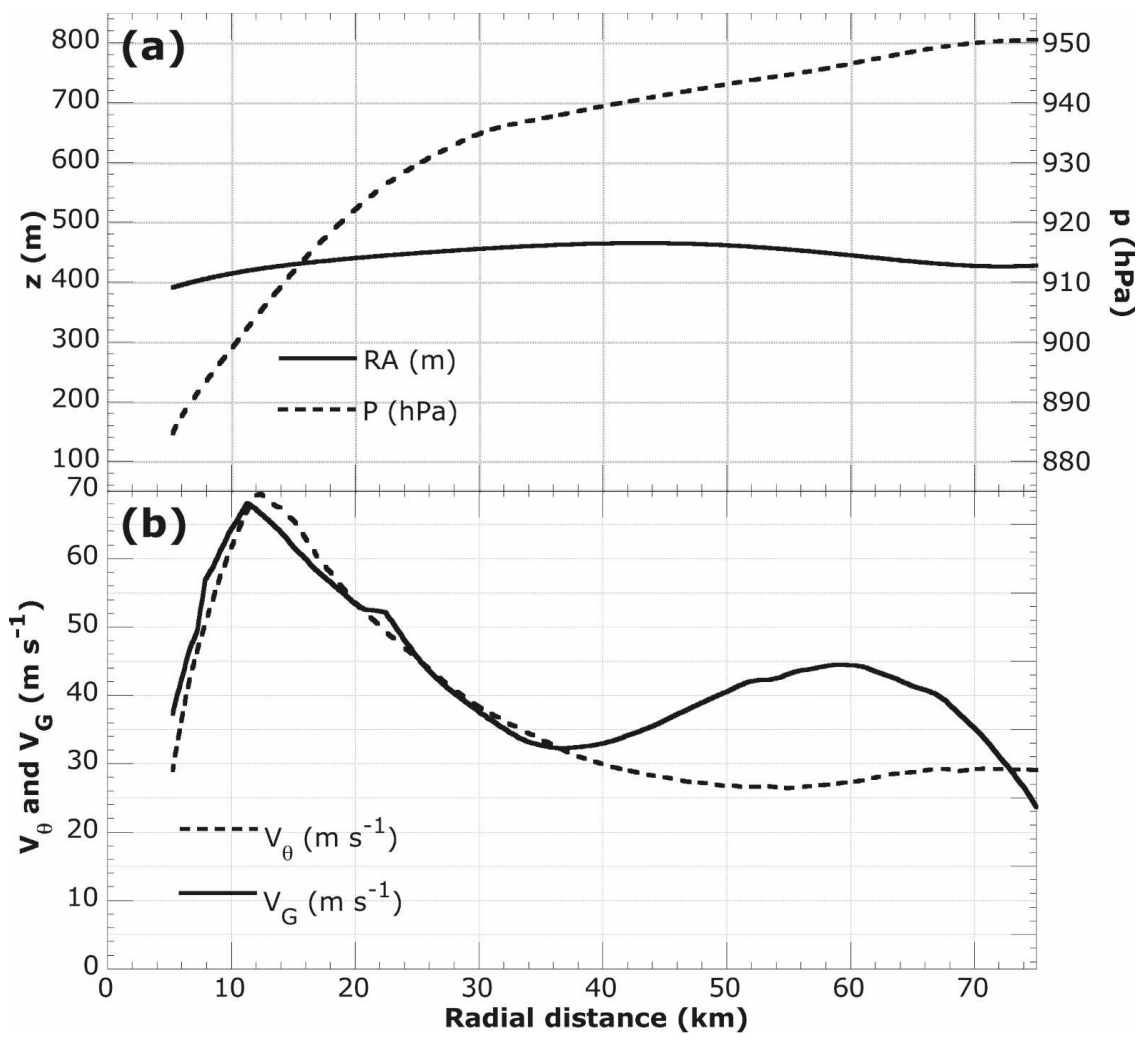

FIG. 15. (a) Radial plot of the 100-s filtered $P$ and RA. (b) Radial plot of 100-s filtered $V_{\theta}$ and $V_{G}$ computed from (4).

$0.5 \mathrm{~km}$, suggesting the EVM is in approximate cyclostrophic balance.

\section{Discussion and interpretation}

\section{a. $E V M$}

The aforementioned observations suggest that the aircraft penetrated a small $(\sim 1 \mathrm{~km})$ EVM along the inner edge Hurricane Hugo's eyewall. This is the first known documented penetration of such a small intense EVM by an aircraft in a hurricane, although vorticity maxima of this type were noted previously and are likely more common than previously believed (e.g., Fletcher et al. 1961; Marks and Houze 1984; Muramatsu 1986; Bluestein and Marks 1987; Willoughby and Black 1996; Hasler et al. 1998; Montgomery et al. 2002; Aberson et al. 2006). The horizontal scale, horizontal pressure anomaly, and vorticity anomaly for the EVM is summarized in Table 1 and compared with other intense atmospheric vortices. The diameter of the EVM was approximately $1 \mathrm{~km}$ at $450-\mathrm{m}$ altitude, which is more than an order of magnitude smaller than the eye diameter of $25 \mathrm{~km}$. This ratio is comparable to that for the size of a suction vortex to its parent tornado (Fujita
1971; Rotunno 1984). The 1-km diameter is also a factor of 10 smaller than a tornado's parent mesocyclone and is about 5 times the size of a typical tornado. Relative to the filtered pressure and wind speed profiles deduced here, the tangential wind and pressure perturbations are roughly $23 \mathrm{~m} \mathrm{~s}^{-1}$ and $12.5 \mathrm{hPa}$, respectively. The former is about a factor of 3 smaller than the primary vortex's maximum tangential winds. In contrast, suction vortices in strong tornadoes are thought to contain local tangential winds about a factor of 2 greater than tornado rotational winds (Fujita 1971; Fiedler 1998). The vorticity maximum of the EVM is $1.25 \times$ $10^{-1} \mathrm{~s}^{-1}$, roughly 7 times the magnitude of the primary vortex and comparable to the vorticity maximum in a weak tornado (e.g., Fujita 1971).

As a first step in interpreting these observations, it is useful to recall the vorticity-mixing model first proposed for TC-like vortices by Schubert et al. (1999). In this simple barotropic nondivergent model, an initially perturbed cyclonic vortex possessing a ring-like vorticity structure breaks down through the growth of barotropic instabilities, forming subvortex-scale vortices that, in the absence of continued vortex-tube stretching by eyewall convection, are distorted and ultimately fila- 


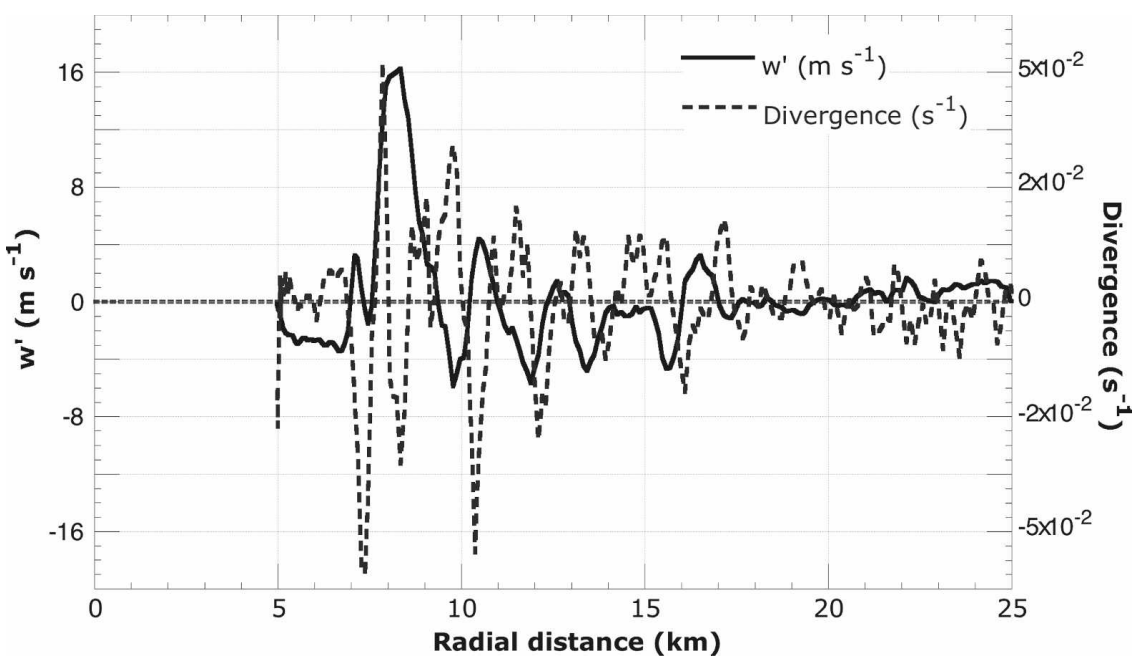

FIG. 16. Radial plot of $w^{\prime}$ and perturbation divergence computed by substituting $V_{r}^{\prime}$ for $V_{r}$ in (2).

mented by the shearing flow of the larger-scale circulation. During the vorticity redistribution process filaments of vorticity are shed away from the core region while the vorticity in the core slowly merges into a monopole (cf. their Fig. 3). This downscale enstrophy cascade of vorticity filaments to small scales and upscale kinetic energy cascade as the vortex reconsolidates into an approximate monopole circulation is consistent with expectations from two-dimensional turbulence theory (e.g., McWilliams 1984, 2006). As the vorticity is redistributed into an approximate monopole, the system-scale pressure field adjusts to the evolving flow, and the final state central pressure is lower than the original vortex. The wind and pressure centers are generally not collocated and instead revolve about the geometric centroid of the vorticity field, an invariant of the model flow.

The structure and evolution of Hugo's primary vortex described here share some similarity with these and other idealized high-resolution numerical modeling experiments. According to the best-track analysis the storm-scale surface pressure started dropping from 957 to $925 \mathrm{hPa} 11 \mathrm{~h}$ prior to LA entering the storm, and continued to drop another $7 \mathrm{hPa}$ in the hour LA circled in the eye [i.e., $39 \mathrm{hPa}$ in $12 \mathrm{~h}$ (Case and Mayfield 1990)]. If the primary vortex possessed a ringlike structure and that ring was barotropically/baroclinically unstable prior to when the aircraft entered the eye, then it is plausible to speculate that vorticity mixing was far along by the time the aircraft arrived.

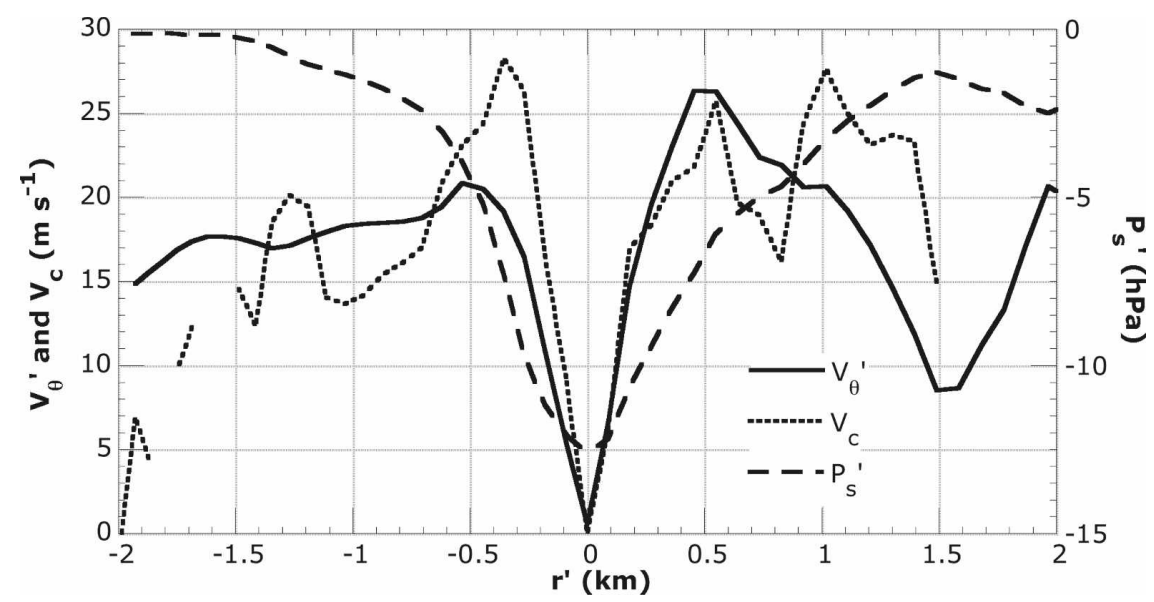

FIG. 17. Radial plot of $P_{s}^{\prime}, V_{\theta}^{\prime}$, and the cyclostrophic wind $\left(V_{c}\right)$ computed from (5) for the $\mathrm{EVM} ; r^{\prime}$ is the radial distance from the center of the EVM. 
TABLE 1. Comparison of the spatial scale and magnitude of intense atmospheric vortices with the Hugo observations.

\begin{tabular}{lccc}
\hline \hline & $\begin{array}{c}\text { Pressure } \\
(\mathrm{km})\end{array}$ & $\begin{array}{c}\text { perturbation } \\
(\mathrm{hPa})\end{array}$ & $\begin{array}{c}\text { Vorticity } \\
\left(\mathrm{s}^{-1}\right)\end{array}$ \\
\hline Hugo primary vortex & 12.5 & 76 & $2 \times 10^{-2}$ \\
Hugo EVM & $1-2$ & 12.5 & $1 \times 10^{-1}$ \\
Mesocyclones & $5-10$ & $3-4$ & $1 \times 10^{-2}$ \\
Tornadoes & $0.25-1.5$ & $15-20$ & 1 \\
Waterspouts & $0.04-0.50$ & $4-5$ & $2 \times 10^{-1}$ \\
\hline
\end{tabular}

Table 2 compares Hurricane Hugo's structure and proposed evolution with barotropic nondivergent numerical simulations reported in Schubert et al. (1999), Montgomery et al. (2000), and Kossin and Schubert (2001). In Schubert et al. (1999), the $r_{\max }$ of the primary vortex was $60 \mathrm{~km}$ and it took 30-36 h to complete the bulk of the mixing process defined as when the rate of change of enstrophy (area-averaged squared vorticity) becomes small (the mixing time in Table 2). Montgomery et al. (2000) examined the mixing process using smaller-scale initial vortices with similar intensity, and Kossin and Schubert (2001) examined the vorticitymixing dynamics with a series of narrow ringlike vortices with $r_{\max }$ between 12 and $17 \mathrm{~km}$. The outcome of these experiments indicates that the smaller the $r_{\max }$ is the faster the mixing process is and that the weaker the initial $\zeta$ ring is the smaller the net (center minus ambient) surface pressure fall of the final vortex is. The observations summarized in Table 2 suggest that Hurricane Hugo's evolution possessed characteristics similar to these latter experiments. Because LA was the first aircraft to fly into Hugo, we can only speculate what the $r_{\max }$, initial $\zeta$, and ring width were when the mixing started, but one plausible interpretation is that the EVM is a natural outcome of the vorticity mixing that began around 0600 UTC when the storm-scale pressure field started to drop precipitously.

There is one important aspect of the EVM that is not represented in the simple barotropic nondivergent simulations summarized above. In these simulations, the vertical vorticity tends to be materially conserved, whereas in reality the vorticity ring is located near the eyewall cloud where, even on the primary vortex scale, there is strong latent heat release and the primary vortex convergence is relatively large (approximately 25\% of the primary vortex vorticity; cf. Fig. 13). In regions where the vorticity annulus breaks down, the emergent vortical structures will experience local convergence and vortex-tube stretching, and some of these vorticity structures are expected to intensify locally over and above the primary vortex values (e.g., Rotunno 1984; Fiedler 1998; Montgomery et al. 2002).

\section{b. Eyewall-scale trochoidal mode}

Earlier analyses using the data obtained during LA's orbits within the eye originally led the first two authors to hypothesize that the EVM was long-lived, making three orbits around the eye in $1 \mathrm{~h}$ (Marks and Black 1990; Black and Marks 1991). Since then, however, an alternative hypothesis was developed here in which the observed evolution of the circulation within the eye is a trochoidal oscillation or wobble of the eye that is expected to stimulate and/or accompany the vorticitymixing process described above. Evidence supporting this hypothesis and its relation to recent theoretical predictions is summarized here.

Following the encounter with the EVM, the aircraft repeatedly penetrated local wind and pressure minima as it orbited within the eye and climbed to a safer altitude. From Fig. 8 it is evident that both the wind and pressure centers exhibited a trochoidal-like oscillation, making three orbits while undergoing a mean translation speed of $9 \mathrm{~m} \mathrm{~s}^{-1}$. The pressure centers lagged the wind centers slightly in time, with a larger orbital radius $(\sim 6.5 \mathrm{~km})$ than that for the wind center $(\sim 2 \mathrm{~km})$. After removing the storm motion, the relative wind and pressure centers are found to orbit around a common locus (see Fig. 9) with a rotation period of approximately 19 min. The longevity $(>1 \mathrm{~h})$ and 19-min rotation period

TABLE 2. Comparison of Hurricane Hugo $r_{\max }$, change in perturbation pressure of primary vortex $\left[\Delta\left(P_{\mathrm{sc}}-P_{\mathrm{s} 100}\right)\right.$; perturbation pressure is defined as the surface pressure at the center $\left(P_{\mathrm{sc}}\right)$ minus the surface pressure at $100 \mathrm{~km}$ radius $\left.\left(P_{\mathrm{s} 100}\right)\right]$, vortex ring $\zeta$ and width, and mixing time with vorticity-mixing experiments.

\begin{tabular}{lccccc}
\hline \hline & $r_{\max }(\mathrm{km})$ & $\Delta\left(P_{\mathrm{sc}}-P_{\mathrm{s} 100}\right)(\mathrm{hPa})$ & $\operatorname{Ring} \zeta\left(\times 10^{-2} \mathrm{~s}^{-1}\right)$ & Ring width $(\mathrm{km})$ & Mixing time $(\mathrm{h})$ \\
\hline Schubert et al. (1999) & 60 & -9 & 0.32 & 30 & $30-36$ \\
Montgomery et al. (2000) & 30 & -12 & 0.64 & 18 & 14 \\
Kossin and Schubert (2001) & 17 & -14 & 2.49 & 4 & 6 \\
& 12 & -11 & 2.25 & 3.38 & 4 \\
\\
Hurricane Hugo (1989) & 12 & -28 & 4.48 & 4 & 11 \\
& 12 & -49 & $\geq 1.85$ & $3-5$ & 12.5 \\
\hline
\end{tabular}


of the wind and pressure centers strongly suggest a persistent wobble of the storm circulation center.

Recent work demonstrated that a trochoidal/wobble motion of the inner core is expected for any tropical cyclone possessing a low-vorticity eye and vorticity perturbations located interior to the angular velocity maximum (e.g., Nolan and Montgomery 2000; Nolan et al. 2001). The trochoidal motion and nonlinear vorticity redistribution that accompanies its excitation and growth to finite amplitude was first discovered by plasma physicists investigating nonneutral hollow-core electron columns (Smith and Rosenbluth 1990). Subsequent work demonstrated the significance of this trochoidal mode and the accompanying vorticity mixing in the eye/eyewall region of tropical cyclone vortices. The trochoidal instability was demonstrated to be robust, operating in barotropic nondivergent vortices and fully three-dimensional baroclinic vortices resembling the inner-core structure of tropical cyclones (Nolan and Montgomery 2000; Nolan et al. 2001). Whereas the rate of growth of the trochoidal mode decreases with the effective depth of the fluid, the rotational period varies weakly and is found to be slightly less than $2 \pi / \Omega_{\max },{ }^{12}$ where $\Omega=V_{\theta} / r$ is the mean angular velocity of the storm-scale circulation (Nolan et al. 2001; Finn et al. 1999). Figure $12 \mathrm{~b}$ shows the radial profile of the 100 -s mean angular velocity; the peak value is $\Omega_{\max } \approx 6 \times$ $10^{-3} \mathrm{~s}^{-1}$. The observed 19-min cyclonic rotation period of both wind and pressure centers is reasonably close to the theoretically predicted value $2 \pi / \Omega_{\max }=17.5 \mathrm{~min}$ for barotropic nondivergent flow. The uncertainty of the effective depth of the fluid in the eye/eyewall region due to the presence of moisture and strongly convergent flow precludes a more precise estimate here. ${ }^{13}$ The reasonable agreement nevertheless supports the hypothesis that the evolution of the circulation center within the eye is consistent with an intrinsic trochoidal wobble motion that is distinct from the EVM encountered by the aircraft.

\section{c. Relation to boundary layer roll-like structures}

If the EVM observed on the penetration is a result of vorticity mixing, then the $\zeta^{\prime}$ and $w^{\prime}$ perturbations outward from the EVM, $r_{\max }$ to $20-\mathrm{km}$ radius in Figs. 13c and $14 \mathrm{c}$, are likely vorticity filaments generated during the vorticity-mixing process and deformed by the azi-

\footnotetext{
${ }^{12}$ Exactly $2 \pi / \Omega_{\max }$ for two-dimensional nondivergent barotropic model, but it is always slower in a divergent flow.

${ }^{13}$ As a first step to consistently account for the dynamical influence of moisture, Schecter and Montgomery (2006) present a novel formulation for waves in a cloudy vortex.
}

muthal shearing flow of the primary vortex. At 450-m altitude the radial scale of these vorticity filaments is $\sim 2 \mathrm{~km}$ and wind perturbations suggest a roll-like structure, with $V_{\theta}^{\prime}$ and $V_{r}^{\prime}$ almost $180^{\circ}$ out of phase (Fig. 13c) and $w^{\prime}$ likely driven by the local divergence of $V_{r}^{\prime}$ (Fig. 16).

Unfortunately, the azimuthal and vertical structure of these filaments is unknown, but recent ground-based Doppler radar observations described by Wurman and Winslow (1998) and Morrison et al. (2005) indicate that such rolls or filaments are present at similar altitudes in the atmospheric boundary layer (ABL) of landfalling TCs. In their observations the rolls or filaments extend 10-20 km along the flow and are centered between 200and 800-m altitude, with very similar radial scales $(800$ $2000 \mathrm{~m}$ versus $2 \mathrm{~km})$ and amplitudes $\left(5-10 \mathrm{~m} \mathrm{~s}^{-1}\right.$ versus $8-12 \mathrm{~m} \mathrm{~s}^{-1}$ ) to those in Fig. 13c.

These filaments or rolls may also explain recent GPS dropwindsonde observations of low-level jets in the eyewall ABL. Franklin et al. (2003) described jets in the vertical profile of the horizontal wind at altitudes $<1$ $\mathrm{km}$ in Hurricanes Guillermo (1997), Erika (1997), Georges (1998), and Mitch (1998). These eyewall soundings indicate numerous low-level wind maxima between 200 and $800 \mathrm{~m}$. These dropwindsonde wind observations are consistent with Australian tower observations in the inner, high-wind core of tropical cyclones first reported by Wilson (1979) and more recently discussed by Kepert and Holland (1997). The magnitude of these jets and the altitudes at which they are observed suggest they may be similar manifestations of the filaments observed in Hurricane Hugo.

The same vortex-mixing processes that generated these filaments may also be responsible for the features observed along the south side of the eyewall and surrounding the aircraft in the tail radar cross sections in Fig. 4. The spatial scale of these radar reflectivity features is close to that of the filaments $(2-3 \mathrm{~km})$ and may be caused by the vertical velocity perturbations associated with the filaments. Bluestein and Marks (1987) suggested that the cloud striations along the inside of the eyewall, which were similar to those seen along the south eyewall in Fig. 4, were associated with some short time- and space-scale instability of the eyewall vorticity sheet (Emanuel 1984). An alternative explanation is that these vorticity perturbations are simply vortex tubes that point radially inward near the ocean surface, turn upward near the bottom of the eyewall, and then coil upwind around the eyewall consistent with the vertical and azimuthal vorticity associated with the mean tangential and vertical velocity, respectively, on the inside edge of the eyewall (cf. Rotunno 1984, section $4 b$ ). 


\section{Conclusions}

The flight and scientific crews aboard LA will not soon forget the penetration of Hurricane Hugo and the subsequent slow, steady climb in its eye on 15 September 1989. Even though the mission objectives were not achieved, the flight inadvertently collected observations of circulation features in the eye and eyewall whose existence was postulated theoretically, and this flight provided the first observational evidence of their presence in an intense hurricane.

Analyses of LA's 1-Hz flight-level observations from the mission's only penetration of Hugo's eye support the existence of a small intense EVM on the cyclonic shear side of the eyewall. To isolate this feature, the flight-level data are partitioned into Hugo's primary vortex and perturbation flow derived from a fast Fourier transform of the vorticity time series. This resulting 100 -s filtered primary vortex is found to be consistent with that constructed from an airborne Doppler radar analysis. Within $25-\mathrm{km}$ radius of the circulation center the flight-level data indicate that the primary vortex is close to gradient balance with a radius of maximum wind of $12.5 \mathrm{~km}$ and a magnitude of $70 \mathrm{~m} \mathrm{~s}^{-1}$. Outside $35-\mathrm{km}$ radius a region of subgradient flow characterized the primary vortex.

The EVM's radius of maximum wind is $\sim 500 \mathrm{~m}$, positioned $8-\mathrm{km}$ radius from the wind center of the primary vortex, and inside its radius of maximum wind. The observations indicate that the EVM's pressure perturbation of $12 \mathrm{hPa}$ was in approximate cyclostrophic balance at the time the aircraft encountered it. The analysis of the EVM is the first documented by an aircraft in a hurricane, although the existence of structures of this type were noted in other studies and may be more common than previously believed.

Following the encounter with the EVM, the aircraft repeatedly penetrated wind and pressure minima as it orbited within the eye while climbing to a safer altitude. It was evident that both the wind and pressure centers exhibited a trochoidal-like wobble with a period of approximately $19 \mathrm{~min}$. The scale $(>15 \mathrm{~km})$, longevity $(>1$ $\mathrm{h}$ ), and 19-min rotation period of the observed pressure and wind centers strongly suggests a persistent wobble of the eye of the storm. The 19-min rotation period is reasonably close to the theoretically predicted value of $17.5 \mathrm{~min}$ for barotropic nondivergent flow.

This study presents the first in situ documentation of these vortical structures, which were recently hypothesized to be elements of a lower-tropospheric eye/ eyewall mixing mechanism that supports strong storms (e.g., Emanuel 1997; Schubert et al. 1999; Persing and
Montgomery 2003; Montgomery et al. 2006; Aberson et al. 2006).

Acknowledgments. The authors thank the flight crews of the NOAA/Aircraft Operations Center (AOC) who fly and maintain the two WP-3D aircraft. Without their skill and dedication, this dataset could not be analyzed. In particular we thank the LA flight crew on this flight: pilots Gerry McKim and Lowell Genzlinger, engineer Steve Wade, navigator Sean White, flight director Jeff Masters, and project manager Jim McFadden for their skill and professionalism. Without it, we would not be here to analyze this dataset. We also thank the AOC electrical engineers and technicians who maintained the aircraft instrumentation during this flight: in particular, Terry Schricker and Alan Goldstein. Without their skill and professionalism, this dataset would not exist. Jim DuGranrut, the former Deputy Director at AOC, helped with the postprocessing of the flight-level data by augmenting the flight-level $1-\mathrm{Hz}$ aircraft attitude information using the $50-\mathrm{Hz}$ information stored on the aircraft radar tapes. We thank fellow scientists from the Hurricane Research Division who were on the flight with us: in particular, Hugh Willoughby and Peter Dodge. Their skill and professionalism were instrumental in the collection of this dataset. We also thank the UA and AFA flight crews who came to our rescue and ably guided us out of the storm and back to base. Last, we thank Wayne Schubert, Jim Kossin, Paul Reasor, and Hugh Willoughby for their encouragement and constructive comments on earlier drafts of this paper. MTM was supported in part by National Science Foundation Grants ATM-0715426 and ATM-0649944, the U.S. Naval Postgraduate School, and NOAA/AOML's Hurricane Research Division. This paper is dedicated to the memory of our coauthor, good friend, and colleague Robert W. Burpee, who died in July 2007, and to that of our close friend and engineer Terry Schricker, who died in June 2007.

\section{APPENDIX}

\section{Nomenclature}

The nomenclature used in this study is given in Table A1.

TABLE A1. Nomenclature of all variables used.

\begin{tabular}{ll}
\hline \hline Variable & \multicolumn{1}{c}{ Description } \\
\hline$f$ & Coriolis parameter \\
$P$ & Flight-level pressure \\
$P_{\text {linear }}$ & Linear variation of surface pressure in time \\
$P_{s}$ & Surface pressure \\
$P_{s}^{\prime}$ & Surface pressure perturbation as a function of \\
& $\quad$ radial distance \\
\hline
\end{tabular}


TABlE A1. (Continued)

\begin{tabular}{ll}
\hline \hline Variable & \\
\hline$P_{s}^{\prime \prime}$ & Surface pressure perturbation from $P_{s}^{\prime}$ \\
$P_{s 100}$ & Surface pressure at $100 \mathrm{~km}$ from the storm center \\
$P_{\mathrm{sc}}$ & Surface pressure at the storm center \\
$r$ & Radial distance from the storm center \\
$r^{\prime}$ & Radial distance from center of EVM \\
$r_{\max }$ & Radius of maximum wind \\
$r_{\max }^{\prime}$ & Radius of maximum wind for the EVM \\
$\mathrm{RA}$ & Radar altitude \\
$V_{C}$ & Cyclostrophic wind \\
$V_{G}$ & Geostrophic wind \\
$V_{\max }$ & Maximum wind \\
$V_{r}$ & Radial wind \\
$V_{r}^{\prime}$ & Radial wind perturbation from 100-s filter \\
$V_{\theta}$ & Tangential wind \\
$V_{\theta}^{\prime}$ & Tangential wind perturbation from 100-s filter \\
$V_{\theta} \max$ & Tangential wind at the radius of maximum wind \\
$w$ & Vertical wind \\
$w^{\prime}$ & Vertical wind perturbation from 100-s filter \\
$\theta_{e}$ & Equivalent potential temperature \\
$\Omega$ & Angular velocity \\
$\rho$ & Density of air \\
$\zeta$ & Vorticity (vertical component) \\
$\zeta^{\prime}$ & Vorticity perturbation from 100-s filter \\
\hline
\end{tabular}

\section{REFERENCES}

Aberson, S. D., M. T. Montgomery, M. Bell, and M. Black, 2006 Hurricane Isabel (2003): New insights into the physics of intense storms. Part II: Extreme localized wind. Bull. Amer. Meteor. Soc., 87, 1349-1354.

Black, M. L., R. W. Burpee, and F. D. Marks, 1996: Vertical motion characteristics of tropical cyclones determined with airborne Doppler radial velocities. J. Atmos. Sci., 53, 1887-1909.

Black, P. G., and F. D. Marks, 1991: The structure of an eyewall meso-vortex in Hurricane Hugo (1989). Preprints, 19th Conf. on Hurricanes and Tropical Meteorology, Miami, FL, Amer. Meteor. Soc., 579-582.

Bluestein, H. B., and F. D. Marks, 1987: On the structure of the eyewall of Hurricane Diana (1984): Comparison of radar and visual characteristics. Mon. Wea. Rev., 115, 2542-2552.

Case, B., and M. Mayfield, 1990: Atlantic hurricane season of 1989. Mon. Wea. Rev., 118, 1165-1177.

Emanuel, K. A., 1984: A note on the stability of columnar vortices. J. Fluid Mech., 145, 235-238.

_ 1997: Some aspects of hurricane inner-core dynamics and energetics. J. Atmos. Sci., 54, 1014-1026.

Fiedler, B., 1998: Wind-speed limits in numerically simulated tornadoes with suction vortices. Quart. J. Roy. Meteor. Soc., 124, 2377-2392.

Finn, J. M., D. del-Castillo-Negrete, and D. C. Barnes, 1999: Compressional effects in non-neutral plasmas, a shallow water analogy and $\mathrm{m}=1$ instability. Phys. Plasmas, 6, 3744-3758.

Fletcher, R. D., J. R. Smith, and R. C. Bundgaard, 1961: Superior photographic reconnaissance of tropical cyclones. Weatherwise, 14, 102-109.

Franklin, J. L., M. L. Black, and K. Valde, 2003: GPS dropwindsonde wind profiles in hurricanes and their operational implications. Wea. Forecasting, 18, 32-44.

Fujita, T. T., 1971: Proposed mechanism of suction spots accom- panied by tornadoes. Preprints, Seventh Conf. on Severe Local Storms, Kansas City, MO, Amer. Meteor. Soc., 208-213.

Hasler, A. F., K. Palaniappan, C. Kambhammetu, P. Black, E. Uhlhorn, and D. Chesters, 1998: High-resolution wind fields within the inner core and eye of a mature tropical cyclone from GOES 1-min images. Bull. Amer. Meteor. Soc., 79, 2483-2496.

Holliday, C. R., and A. H. Thompson, 1979: Climatological characteristics of rapidly intensifying typhoons. Mon. Wea. Rev., 107, 1022-1034.

Jorgensen, D. P., 1984a: Mesoscale and convective-scale characteristics of mature hurricanes. Part I: General observations by research aircraft. J. Atmos. Sci., 41, 1268-1285.

- 1984b: Mesoscale and convective-scale characteristics of mature hurricanes. Part II: Inner core structure of Hurricane Allen (1980). J. Atmos. Sci., 41, 1287-1311.

Kepert, J. D., and G. J. Holland, 1997: The Northwest Cape tropical cyclone boundary layer monitoring station. Preprints, 22nd Conf. on Hurricanes and Tropical Meteorology, Ft. Collins, CO, Amer. Meteor. Soc., 82-83.

Kossin, J. P., and W. H. Schubert, 2001: Mesovortices, polygonal flow patterns, and rapid pressure falls in hurricane-like vortices. J. Atmos. Sci., 58, 2196-2209.

Lee, W.-C., F. D. Marks, and R. Carbone, 1994: Velocity track display-A technique to extract real-time tropical cyclone circulations using a single airborne Doppler radar. J. Atmos. Oceanic Technol., 11, 337-356.

Mallen, K. J., M. T. Montgomery, and B. Wang, 2005: Reexamining the near-core radial structure of the tropical cyclone primary circulation: Implications for vortex resiliency. J. Atmos. Sci., 62, 408-425.

Marks, F. D., 1985: Evolution of the structure of precipitation in Hurricane Allen (1980). Mon. Wea. Rev., 113, 909-930.

— tions in Hurricane Debby. Bull. Amer. Meteor. Soc., 65, 569582.

, and - 1987: Inner core structure of Hurricane Alicia from airborne Doppler radar observations. J. Atmos. Sci., 44, 1296-1317.

_ and P. G. Black, 1990: Close encounter with an intense mesoscale vortex within Hurricane Hugo (September 15, 1989). Extended Abstracts, Fourth Conf. on Mesoscale Processes, Boulder, CO, Amer. Meteor. Soc., 114-115.

— R. A. Houze, and J. F. Gamache, 1992: Dual-aircraft investigation of the inner core of Hurricane Norbert. Part I: Kinematic structure. J. Atmos. Sci., 49, 919-942.

McWilliams, J. C., 1984: The emergence of isolated coherent vortices in turbulent flow. J. Fluid Mech., 146, 21-43.

_ 2006: Fundamentals of Geophysical Fluid Dynamics. Cambridge University Press, 249 pp.

Montgomery, M. T., and R. J. Kallenbach, 1997: A theory for vortex Rossby waves and its application to spiral bands and intensity changes in hurricanes. Quart. J. Roy. Meteor. Soc., 123, 435-465.

, J. M. Hidalgo, and P. D. Reasor, 2000: A semi-spectral numerical method for modeling the vorticity dynamics of the near-core of hurricane-like vortices. Atmospheric Science Paper 695, Dept. of Atmospheric Science, Colorado State University, $56 \mathrm{pp}$.

—, V. A. Vladimirov, and P. V. Denissenko, 2002: An experimental study on hurricane mesovortices. J. Fluid Mech., 471, 1-32.

_ M. M. Bell, S. D. Aberson, and M. L. Black, 2006: Hurricane 
Isabel (2003): New insights into the physics of intense storms. Part I: Mean vortex structure and maximum intensity estimates. Bull. Amer. Meteor. Soc., 87, 1335-1347.

Morrison, I., S. Businger, F. D. Marks, P. P. Dodge, and J. Businger, 2005: An observational case for the prevalence of roll vortices in the hurricane boundary layer. J. Atmos. Sci., 62, 2662-2673.

Muramatsu, T., 1986: The structure of polygonal eye of a typhoon. J. Meteor. Soc. Japan, 64, 913-921.

Nolan, D. S., and M. T. Montgomery, 2000: The algebraic growth of wavenumber one disturbances in hurricane-like vortices. $J$. Atmos. Sci., 57, 3514-3538.

, - - and L. D. Grasso, 2001: The wavenumber-one instability and trochoidal motion of hurricane-like vortices. J. Atmos. Sci., 58, 3243-3270.

Persing, J., and M. T. Montgomery, 2003: Hurricane superintensity. J. Atmos. Sci., 60, 2349-2371.

Rotunno, R., 1984: An investigation of a three-dimensional asymmetric vortex. J. Atmos. Sci., 41, 283-298.

Roux, F., and F. D. Marks, 1996: Extended Velocity Track Display (EVTD): An improved processing method for Doppler radar observations of tropical cyclones. J. Atmos. Oceanic Technol., 13, 875-899.

Saffir, H. S., 1973: Hurricane wind and storm surge. Mil. Eng., 423, 4-5.

Schecter, D. A., and M. T. Montgomery, 2006: Conditions that inhibit the spontaneous radiation of spiral inertia-gravity waves from an intense mesoscale cyclone. J. Atmos. Sci., 63 435-456.

Schubert, W. H., M. T. Montgomery, R. K. Taft, T. A. Guinn, S. R. Fulton, J. P. Kossin, and J. P. Edwards, 1999: Polygonal eyewalls, asymmetric eye contraction, and potential vorticity mixing in hurricanes. J. Atmos. Sci., 56, 1197-1223.

Simpson, R. H., 1974: The hurricane disaster potential scale. Weatherwise, 27, 169-186.

Smith, R. A., and M. N. Rosenbluth, 1990: Algebraic instability of hollow electron columns and cylindrical vortices. Phys. Rev. Lett., 64, 649-652.

Willoughby, H. E., 1990: Gradient balance in tropical cyclones. $J$. Atmos. Sci., 47, 265-274.

- and M. B. Chelmow, 1982: Objective determination of hurricane tracks from aircraft observations. Mon. Wea. Rev., 110, 1298-1305.

— namics of a disaster. Bull. Amer. Meteor. Soc., 77, 543-549.

- J. A. Clos, and M. G. Shoreibah, 1982: Concentric eye walls, secondary wind maxima, and the evolution of the hurricane vortex. J. Atmos. Sci., 39, 395-411.

Wilson, K. J., 1979: Characteristics of the subcloud layer wind structure in tropical cyclones. Extended Abstracts, Int. Conf. on Tropical Cyclones, Perth, Australia, Roy. Meteor. Soc. (Australian Branch), 15II.

Wurman, J., and J. Winslow, 1998: Intense sub-kilometer-scale boundary layer rolls observed in Hurricane Fran. Science, 280, 555-557. 